\title{
Cardiovascular Disease in Latin American Patients with Systemic Lupus Erythematosus: A Cross-Sectional Study and a Systematic Review
}

\author{
Jenny Amaya-Amaya, Juan Camilo Sarmiento-Monroy, \\ Julián Caro-Moreno, Nicolás Molano-González, Rubén D. Mantilla, \\ Adriana Rojas-Villarraga, and Juan-Manuel Anaya \\ Center for Autoimmune Diseases Research (CREA), School of Medicine and Health Sciences, Universidad del Rosario, \\ Carrera 24 No. 63C-69, 111221 Bogotá, Colombia
}

Correspondence should be addressed to Jenny Amaya-Amaya; jecamaya@gmail.com

Received 27 June 2013; Accepted 26 August 2013

Academic Editor: Yehuda Shoenfeld

Copyright ( $) 2013$ Jenny Amaya-Amaya et al. This is an open access article distributed under the Creative Commons Attribution License, which permits unrestricted use, distribution, and reproduction in any medium, provided the original work is properly cited.

Objective. This study was performed to determine the prevalence of and associated risk factors for cardiovascular disease (CVD) in Latin American (LA) patients with systemic lupus erythematosus (SLE). Methods. First, a cross-sectional analytical study was conducted in 310 Colombian patients with SLE in whom CVD was assessed. Associated factors were examined by multivariate regression analyses. Second, a systematic review of the literature on CVD in SLE in LA was performed. Results. There were 133 (36.5\%) Colombian SLE patients with CVD. Dyslipidemia, smoking, coffee consumption, and pleural effusion were positively associated with CVD. An independent effect of coffee consumption and cigarette on CVD was found regardless of gender and duration of disease. In the systematic review, 60 articles fulfilling the eligibility criteria were included. A wide range of CVD prevalence was found (4\%-79.5\%). Several studies reported ancestry, genetic factors, and polyautoimmunity as novel risk factors for such a condition. Conclusions. A high rate of CVD is observed in LA patients with SLE. Awareness of the observed risk factors should encourage preventive population strategies for CVD in patients with SLE aimed at facilitating the suppression of cigarette smoking and coffee consumption as well as at the tight control of dyslipidemia and other modifiable risk factors.

\section{Introduction}

Systemic lupus erythematosus (SLE) is a complex systemic autoimmune disease $(\mathrm{AD})$, characterized by the production of numerous pathogenic autoantibodies [1]. Diverse heritable, hormonal, and environmental factors and immunesystem aberrations contribute to the clinical expression of the disease [2]. The heterogeneous nature of SLE explains the broad spectrum of clinical manifestations (i.e., subphenotypes). SLE affects predominantly women (female-to-male ratio 9:1) of child-bearing age [3]. The annual incidence and prevalence range from 1.4 to 11 cases per 100,000 population, and from 7.4 to 159.4 cases per 100,000 population, respectively [4] depending on a variety of factors, including age, gender, and ancestry. African, Hispanic, and Asian ancestry significantly influence both the risk of developing the disorder and outcome [4]. A bimodal mortality was described by Urowitz et al. [5] characterized by an early peak in the first 3 years after diagnosis due to active disease, infections and glomerulonephritis, and a second peak, 4-20 years after SLE diagnosis, in which cardiovascular disease (CVD) is the main feature and cause of death. Although overall mortality for patients with SLE has improved over the past 30 years, mortality due to CVD has remained almost the same [6].

CVD is the leading cause of mortality, responsible for about $30 \%$ of deaths worldwide. Globally, $80 \%$ of total CVD deaths occur in developing countries [7]. In addition, there is strong epidemiologic evidence that CVD risk among SLE patients compared to the general population is at least doubled [8]. Noteworthy, the excessive cardiovascular (CV) 
events observed in SLE individuals are not fully explained by classic risk factors. Several SLE-specific factors, including disease activity and duration, and possibly specific manifestations and therapies, further increase CV risk [8]. In fact, SLE per se seems to be an independent risk factor for the development of accelerated atherosclerosis [9].

SLE is not uncommon in Latin America (LA), the geographical area defined by Mexico, Central America, South America, and the islands of the Caribbean, a rapidly growing region with almost 600 million inhabitants [10]. Latin Americans are considered a highly admixed population due to a mixed ethnicity (so called mestizos) that is mainly derived from a European and Amerindian inheritance [11]. The increased prevalence of chronic diseases in LA has been attributed to diverse causes including the ageing of the population and lifestyle factors such as smoking, physical inactivity, and excess alcohol intake [12]. Despite important advances in recent decades, LA remains one of the world's most unequal regions [13]. Enormous cultural differences in health perceptions in LA exist, correlating with individuals' economic and health conditions [12]. So far, some studies regarding SLE have documented differences in health status, disease prevalence, treatment outcomes, and healthcare use among different ethnic groups, suggesting that minorities influence SLE health disparities [14-19]. Thus, this study was performed to determine the prevalence and associated risk factors for CVD in Latin American patients with SLE.

\section{Material and Methods}

2.1. Study Population. First, a cross-sectional analytical study was conducted in 310 Colombian patients with SLE in whom CVD was assessed. The subjects were seen at the Center for Autoimmune Diseases Research (CREA) in Bogota, Colombia. All of them fulfilled the 1997 update American College of Rheumatology classification criteria for SLE [20]. This study was done in compliance with Act 008430/1993 by Ministry of Health of the Republic of Colombia, which classified it as a minimal-risk research. The institutional review board of the Universidad del Rosario approved the study design.

Information on patient socio-demographic and cumulative clinical and laboratory data, as well as household description, were obtained by interview, standardized report form, physical examination and chart review. All data were collected in an electronic and secure database. Socio-demographic variables included age at SLE onset, disease duration, educational and socioeconomic status, current occupation, smoking habits, coffee consumption, expositional factors and physical activity. Age at onset of the disease was defined as the first subjective experience of the symptom(s) and/or sign(s) described in any of the items of the classification criteria [21]. Duration of disease was considered as the difference between age at onset and the date of first participation in the study. Educational level was recorded as the number of years of education and was divided into two groups (more or less than 9 years) of education based on the "General Law of Education" in Colombia [22, 23]. Socioeconomic status was categorized on the basis of national legislation and was divided into low (1 and 2) and high (3-6) status. Smoking habits was assessed as ever; $1-6,6-15$, and $>15$ packages/year; or quitter cigarette consumption. Coffee intake was asked as yes or not, and measured in cups per day $(1-2,2-4,>4)$. Several expositional factors were also questioned, including the use of silicone implants, hair dyes, pesticides and organic solvents [24].

2.2. Clinical Variables. Clinical and laboratory variables were registered as present or absent at any time during the course of the disease. Clinical features of the disease were included taking into account the revised American College of Rheumatology criteria [20] and others manifestations as follows: polyautoimmunity (coexistence of an additional $\mathrm{AD}$ in the same individual on the basis of international criteria) $[25,26]$, multiple autoimmune syndrome (presence of more than two AD in the same patient) [26-28]; familial autoimmunity, and familial autoimmune disease were also registered as the presence of any other AD and SLE in first degree relatives (FDR) respectively [27-29]. Regarding pharmacological treatment, current or past use of azathioprine, mycophenolate mofetil, cyclophosphamide, methotrexate, antimalarials (i.e., clhoroquine, hydroxychloroquine), glucocorticoids (i.e., prednisolone, metilprednisolone, and deflazacort), and biological therapy (i.e., Rituximab) were recorded.

2.3. Cardiovascular Assessment. Five subphenotypes were defined and assessed: first, hypertension, defined as having a blood pressure $\geq 140 / 90 \mathrm{~mm} \mathrm{Hg}$ or using any antihypertensive medication [30]: systolic and diastolic blood pressures were measured twice with at least a 15 -minute interval between and the averages were recorded. Second, history of stroke, third, coronary event (i.e., unstable angina, myocardial infarction (MI)), fourth, thrombotic event (other than coronary disease and carotid involvement, requiring anticoagulant treatment), fifth, carotid disease (doppler criteria or intima-media thickness $\geq 0.9$ ).

2.4. Laboratories Measurements. Relevant laboratory variables associated with SLE were recorded. Antinuclear antibodies, antidouble strand DNA antibodies, precipitating antibodies to extractable nuclear antigens (Sm, U1-RNP, Ro/SSA, La/SS-B), anticardiolipin IgG and IgM, antibeta 2-glycoprotein $1 \mathrm{IgG}$ and IgM antibodies, and lupus anticoagulant were extracted from the patient's clinical record. Other autoantibodies including rheumatoid factor, anticyclic citrullinated peptide, -thyroperoxidase enzyme, -thyroglobulin, -Scl 70, -centromere, -mitochondrial, and -smooth muscle antibodies were also recorded. Inflammatory biomarkers, including erythrocyte sedimentation rate (ESR), and serum high sensitive C-reactive protein (CRP) levels, as well as white blood cell and platelet count, hemoglobin levels, mean corpuscular volume, coombs test, complement (i.e., C3 and C4 levels), TSH, tetraiodothyronine T4, venereal disease research laboratory, and creatinine were extracted from patient's clinical record. Likewise, serum levels of total cholesterol (TC), triglycerides (TGL), high-density lipoprotein cholesterol (HDL), low-density lipoprotein cholesterol (LDL), and glycemia were determined by blood tests provided by every patient. 
2.5. Assessment of Traditional Risk Factors for CVD. Patients were assessed for traditional CVD risk factors including current age ( $\geq 45$ and $\geq 55$ years for men and women, resp.) [31-34]. Type 2 diabetes mellitus (T2DM) was defined as having a fasting plasma glucose level $\geq 7 \mathrm{mmol} / \mathrm{L}(126 \mathrm{mg} / \mathrm{dL})$, or taking any antidiabetic agents at the time of assessment [35]. A diagnosis of dyslipidemia was given if the patient had (a) hypercholesterolemia, defined as taking lipid-lowering medication as a surrogate, or having a fasting plasma TC $\geq 200 \mathrm{mg} / \mathrm{dL}$ (b) HDL $\leq 40 \mathrm{mg} / \mathrm{dL}$, (c) hypertriglyceridemia (TGL $\geq 150 \mathrm{mg} / \mathrm{dL})$, or (d) elevated LDL ( $\geq 100 \mathrm{mg} / \mathrm{dL})$ [31, 36]. Current hemoglobin $\leq 12 \mathrm{~g} / \mathrm{dL}$ established a diagnosis of anemia and current levels of creatinine (abnormal defined as $\geq 1.2 \mathrm{mg} / \mathrm{dL}$ ) were evaluated as well. History of premature CAD in FDR was also assessed [37]. Patients and their past medical records were evaluated for the current or past use of aspirin or hormone replacement therapy.

2.6. Statistical Analysis. First, univariate analyses were done. Categorical variables were analyzed by frequencies. Kolmogorov-Smirnov normality test was done to evaluate normality for quantitative continuous variables. Parametric data are expressed as the mean and standard deviation, and nonparametric data are described as the median and interquartile range. Second, associations between traditional and nontraditional CVD risk factors were assessed by bivariate analyses. The presence of CVD was assessed through chi square tests or Fisher's exact tests when the variable was dichotomous. Parametric values were analyzed by $t$ student test. Nonparametric values were analyzed by Mann-Whitney $U$ test. Clinical variables with a $P \leq 0.25$ were included in a multivariable model. Finally, a multivariate binomial logistic regression model having CVD as the dependent variable was fit. As independent factors, the model included the traditional and nontraditional associations that were statistically significant in bivariate analyses and those variables that were biologically plausible. Moreover, other logistic regression models were made, including interactions between independent factors. In both circumstances, the models were adjusted by gender and duration of the disease. Adequacies of logistic models were assessed using the Hosmer-Lemeshow goodness-of-fit test. The Nagelkerke $R^{2}$ (i.e., pseudo- $R^{2}$ ) was used to estimate the percentage of variance explained by the models. Adjusted odds ratios (AOR) were calculated with $95 \%$ confidence intervals (CI). The Wald statistic test was used to evaluate the significance of individual logistic regression coefficients for each independent variable. Statistical analyses were done by the Statistical Package for the Social Sciences (SPSS, v.20, Chicago, IL, USA).

2.7. Systematic Review of Literature. The Preferred reporting items for Systematic Reviews and Meta-analyses guidelines were followed [38] to systematically search in the following databases: PubMed, EMBASE, Scopus, SciELO, and Virtual Health Library - which includes BIREME, LILACS and many others LA sources-about CVD and SLE in LA population. Three reviewers did the search and extraction data independently (AAJC, SMJC, and CMJ) using predefined eligibility criteria, from inception up to February 2013.
The search was done in PubMed, using the following Medical Subject Headings (MeSH terms) groups: "Lupus Erythematosus, Systemic," "Cardiovascular Diseases;" "Latin America," "Ethnic Groups," "Brazil," "Mexico," "Colombia," "Chile," “Cuba," "Panama," "Venezuela," "Bolivia," “Peru," "Argentina," "Uruguay," "Paraguay," "Ecuador," "Nicaragua," "Surinam," "French Guiana," "Guatemala," "Honduras," "Belize," "Costa Rica," “El Salvador," "Puerto Rico," “Dominican Republic," and "Haiti." Each one of them was crossreferenced with the following $\mathrm{MeSH}$ terms/keywords: "risk factors," "traditional risk factors," "classic risk factors," "nontraditional risk factors," "novel risk factors," "hypertension," "metabolic syndrome, "obesity," "smoking," "tobacco," "dyslipidemia," "advanced age," "menopausal status," "family history of CVD," "hyperhomocysteinemia," "sedentary lifestyle," "renal impairment," "male gender," "type 2 diabetes mellitus," "insulin resistance," "hormone replacement therapy," "coffee," "ancestry," "polymorphism, genetic," "poliautoimmunity," "autoantibodies," "antibodies, antiphospholipid," "lupus coagulation inhibitor," "circulation anticoagulants," "antibodies, anticardiolipins," "beta 2-glycoprotein I," "endothelial cells antibodies," "systemic inflammation," "c-reactive protein," "blood sedimentation," "tumor necrosis factor," "cytokines," "immune complex," "disease activity," "SLEDAI," "organ damage," "SDI," "duration of illness," "immune cells aberrations," "glucocorticoids," "steroids," "DMARD," "antirheumatic agents," "methotrexate," "biological therapy," "rituximab," "anti-Inflammatory agents, non-steroidal," "azathioprine," "vasculopathy," "lupus nephritis," "premature menopause," "endogenous dyslipidemia," "sociodemographic factors," "hypovitaminosis D," "vitamin D deficiency," "low vitamin D," "osteoporosis," "biomarkers," "antiphospholipid syndrome," "thyroiditis, autoimmune," "Graves Disease," "Hashimoto Disease," "scleroderma," "Sjögren's syndrome," "rheumatoid arthritis," "hypertension," "ischemic heart disease," "coronary artery disease," "acute coronary syndrome," "congestive heart failure," "myocardial infarction," "stroke," "angina," "thrombosis," "deep vein thromboses," "pulmonary embolism," "periphery arterial disease," and "atherosclerosis." Each term was cross-referenced for the greatest number of results. No limits regarding language, period of publication, or publication type were used.

The same terms were used for searching in EMBASE and Scopus databases. Each MeSH term and keyword was translated into DeCS (Health Sciences Descriptors) in order to explore sources of information in Spanish, Portuguese, and English through SciELO and Virtual Health Library databases.

2.8. Study Selection, Data Extraction, and Quality Assessment. Reviewers screened all titles and abstracts and applied the eligibility criteria in order to identify studies that were appropriate for inclusion [39]. A study was included if (a) the abstract was available, (b) it contained original data, (c) it used accepted classification criteria for SLE, (d) it measured $\mathrm{CV}$ risk factors (traditional and/or nontraditional), (e) it examined as a clinical endpoints: hypertension, ischemic heart disease (IHD), coronary artery disease (CAD), acute coronary syndrome (ACS), MI, angina, congestive heart 
failure (CHF), stroke, thrombosis, peripheral arterial disease (PAD), and subclinical atherosclerosis, and (d) it includes LA population. In order to complete the systematic review, several authors were contacted by E-mail for full text and those references from the articles that seemed to be relevant to the review were hand-searched.

Articles were excluded from the analysis if they dealt with juvenile SLE or were done on animal models (i.e., murine models) instead of SLE patients. Studies were also excluded if they were reviews or case reports, or if they discussed topics not related to CVD, and/or were not done on LA population. Blinded reviewers (AAJC, SMJC, and MJC) organized selected articles on the basis of publication source, country, author, year, type of study, sample size, traditional and nontraditional risk factors, cardiovascular outcomes evaluated, and main results. Only novel risk factors with statistical significance were included. For details, see Supplementary Table S1 in the supplementary material available online at http://dx.doi.org/10.1155/2013/794383. Each record was classified based on the quality score of the studies that was assigned by applying the levels established by the Oxford Centre for Evidence-based Medicine 2011 in order to evaluate the risk of bias [40]. The search results were compared and disagreements were resolved by consensus.

\section{Results}

3.1. Description of the Study Population. Out of a total of 310 patients, $91.3 \%(283 / 310)$ were women. The median (interquartile range) of age and duration of the disease was 37 (22) and 5 (9) years, respectively. CVD was observed in $36.5 \%$ $(113 / 310)$. The most frequent condition was hypertension (25.2\%) (Tables 1 and 2).

3.2. Factors Associated with CVD. Current age, ever smoking, coffee consumption, polyautoimmunity (i.e., antiphospholipid syndrome), dyslipidemia, use of cytotoxic drugs, serositis, renal involvement (i.e., nephrotic syndrome), and thrombocytopenia were all risk factors significantly associated with CVD. Instead, ethnicity and leukopenia were factors negatively associated with CVD (Table 3).

3.3. Adjusted Effects of Risk Factors for CVD. Dyslipidemia, pleural effusion, polyautoimmunity, and renal compromise were variables significantly associated with CVD, regardless of gender and duration of the disease by logistic regression analysis (Table 4). The association between CVD and smoking habit remained statistically significant after establishing interaction with coffee consumption (Table 5).

3.4. Systematic Literature Review. There were 21,161 articles identified in PubMed, EMBASE, and Scopus databases search. Additional records identified through other sources included 814 articles (SciELO and Virtual Health Library). Therefore, the database searches provided a total of 21,975 publications. Of these, 19,729 were identified as duplicates. A total of 2,246 full text articles were assessed for eligibility. Only 115 articles were included for methodological analysis.
TABLE 1: Demographic and clinical characteristics of 310 patients with SLE.

\begin{tabular}{|c|c|}
\hline Characteristic & Median (IQR) \\
\hline Age $(y)$ & $37(22)$ \\
\hline Duration of disease $(y)$ & $5.0(9.0)$ \\
\hline Characteristic & Mean (SD) \\
\hline Age at SLE onset (y) & $38(15.4)$ \\
\hline Age of diagnosis $(y)$ & $39.8(15.8)$ \\
\hline Sociodemographic characteristic & $\%(n / N)$ \\
\hline Female & $91.3(283 / 310)$ \\
\hline High education level & $85.6(255 / 298)$ \\
\hline High socioeconomic status & $79.5(236 / 297)$ \\
\hline Mixed occupation & $23.2(71 / 306)$ \\
\hline Housewife & $21.2(65 / 306)$ \\
\hline Exposure to hair dyes & $40.6(125 / 308)$ \\
\hline Clinical manifestation & $\%(n / N)$ \\
\hline Cutaneous compromise & $88.1(273 / 310)$ \\
\hline Arthropathy & $87.7(272 / 310)$ \\
\hline Neurological involvement & $10(31 / 310)$ \\
\hline Hematological criteria & $34.5(107 / 310)$ \\
\hline Immunological criteria & $78.1(242 / 310)$ \\
\hline Raynaud's phenomenon & $39.4(122 / 310)$ \\
\hline Vasculitis & $18.4(57 / 310)$ \\
\hline Alopecia & $47.7(148 / 310)$ \\
\hline Livedo reticularis & $19(59 / 310)$ \\
\hline Pleural effusion & $23.5(73 / 310)$ \\
\hline Pulmonary hypertension & $6.5(20 / 310)$ \\
\hline Pulmonary embolism & $2.9(9 / 310)$ \\
\hline Pericarditis & $14.5(45 / 310)$ \\
\hline Lupus nephritis & $46.5(144 / 310)$ \\
\hline Nephritic syndrome & $5.5(17 / 310)$ \\
\hline Nephrotic syndrome & $16.8(58 / 310)$ \\
\hline \multicolumn{2}{|l|}{ Histological pattern } \\
\hline Normal & $8.5(7 / 82)$ \\
\hline Mesangial glomerulonephritis & $15.9(13 / 82)$ \\
\hline Focal segmental glomerulonephritis & $13.4(11 / 82)$ \\
\hline Proliferative glomerulonephritis & $41.5(34 / 82)$ \\
\hline Membranous glomerulonephritis & $11(9 / 82)$ \\
\hline Autoimmune disease(s) & $\%(n / N)$ \\
\hline Polyautoimmunity & $26.1(81 / 310)$ \\
\hline MAS & $6.1(19 / 310)$ \\
\hline Familial autoimmunity in FDR & $30.3(94 / 310)$ \\
\hline RA & $3.9(12 / 310)$ \\
\hline APS & $8.7(27 / 310)$ \\
\hline SS & $8.7(27 / 310)$ \\
\hline AITD & $6.8(21 / 310)$ \\
\hline
\end{tabular}


TABLE 1: Continued.

\begin{tabular}{|c|c|}
\hline Characteristic & Median (IQR) \\
\hline Comorbidities & $\%(n / N)$ \\
\hline Fibromyalgia & $9.7(30 / 309)$ \\
\hline Depression & $21.4(66 / 309)$ \\
\hline Epilepsy & $3.9(12 / 309)$ \\
\hline Peptic ulcer disease & $38.5(119 / 309)$ \\
\hline Anemia & $8.1(25 / 309)$ \\
\hline Osteoporosis & $5.8(18 / 309)$ \\
\hline Malaria & $2.3(7 / 303)$ \\
\hline Hepatitis A & $7.1(22 / 309)$ \\
\hline Miscarriage & $20.2(57 / 282)$ \\
\hline Drugs & $\%(n / N)$ \\
\hline Azathioprine & $33.9(105 / 310)$ \\
\hline Antimalarial & $80.6(250 / 310)$ \\
\hline Mycophenolate Mofetil & $15.8(49 / 310)$ \\
\hline Steroid & $78.4(243 / 310)$ \\
\hline Rituximab & $7.4(23 / 310)$ \\
\hline Cytotoxic agents & $12.3(38 / 310)$ \\
\hline Biological treatment & $8.4(26 / 310)$ \\
\hline Methotrexate & $34.8(108 / 310)$ \\
\hline Laboratories findings & $\%(n / N)$ \\
\hline Anemia & $25.9(76 / 293)$ \\
\hline Leukopenia & $38(114 / 300)$ \\
\hline Lymphopenia & $78.7(85 / 202)$ \\
\hline Thrombocytopenia & $7.8(23 / 296)$ \\
\hline C-reactive protein $(+)$ & $35.4(57 / 161)$ \\
\hline Erythrocyte sedimentation rate $(+)$ & $46.2(104 / 225)$ \\
\hline $\operatorname{VDRL}(+)$ & $24.5(26 / 204)$ \\
\hline Abnormal serum creatinine & $9.7(26 / 268)$ \\
\hline Abnormal creatinine clearance & $56.6(94 / 166)$ \\
\hline 24 hours proteinuria $(+)$ & $37.7(80 / 212)$ \\
\hline Hematuria & $57.4(58 / 101)$ \\
\hline Pyuria & $36.1(56 / 155)$ \\
\hline Antinuclear antibodies $(+)$ & $98.6(287 / 291)$ \\
\hline Lupus anticoagulant $(+)$ & $51(52 / 102)$ \\
\hline Anti-dsDNA antibodies $(+)$ & $54.6(147 / 269)$ \\
\hline Low complement 3 (C3) & $60.8(160 / 263)$ \\
\hline Low complement 4 (C4) & $31.4(83 / 264)$ \\
\hline aCL IgG (+) & $33.8(79 / 234)$ \\
\hline aCL IgM (+) & $32.4(73 / 225)$ \\
\hline Beta 2-glycoprotein antibodies IgG (+) & $29.4(10 / 34)$ \\
\hline Beta 2-glycoprotein antibodies IgM (+) & $28.6(6 / 21)$ \\
\hline Anti-Ro antibodies $(+)$ & $48.6(122 / 251)$ \\
\hline Anti-La antibodies $(+)$ & $26.2(64 / 244)$ \\
\hline Anti-Sm antibodies $(+)$ & $36(89 / 247)$ \\
\hline Anti-RNP antibodies $(+)$ & $46(109 / 237)$ \\
\hline
\end{tabular}

TABle 1: Continued.

\begin{tabular}{lc}
\hline Characteristic & Median (IQR) \\
\hline Rheumatoid factor $(+)$ & $34.6(27 / 78)$ \\
Citrullinated peptide antibodies $(+)$ & $34.3(12 / 35)$ \\
Thyroid stimulating hormone $(+)$ & $51.5(53 / 207)$ \\
Thyroid peroxidase antibodies $(+)$ & $38.6(17 / 44)$ \\
Thyroglobulin antibodies $(+)$ & $20(6 / 30)$ \\
\hline
\end{tabular}

CVD: cardiovascular disease; SLE: systemic lupus erythematosus; IQR: interquartile range; SD: standard deviation; Y: years; MAS: multiple autoimmune syndrome; FDR: first-degree relatives; RA: rheumatoid arthritis; APS: antiphospholipid syndrome; SS: Sjögren's syndrome; AITD: autoimmune thyroid disease; VDRL: venereal disease research laboratory; aCL: anticardiolipin antibodies.

Arthropathy was defined as the presence of at least one of the following: arthritis, arthralgia, hands edema, or Jaccoud's arthropathy.

Cutaneous compromise was defined as the presence of at least one of the following: photosensitivity, oral ulcers, malar rash, discoid lupus, subacute lupus, and urticaria.

Neurological involvement were defined as the presence of at least one of the following: seizures, psychosis, and peripheral nerve compromise.

Hematological criteria were defined as the presence of at least one of the following: hemolytic anemia, leukopenia, lymphopenia, and thrombocytopenia.

Immunological criteria were defined as the presence of at least one of the following: anti-dsDNA, anti-Sm, anticardiolipin IgG or IgM, lupus anticoagulant, false-positive test VDRL, or fluorescent treponemal antibody absorption test.

Finally, 60 articles that had interpretable data and fulfilled the eligibility criteria were included. In 3 papers, data extraction was made from abstract [41-43]. For details, see Supplementary Table S1. There were 29 from Brazil [42, 44-71], 14 from Mexico [43, 72-84], 6 from United States of America [1618, 85-87], 5 from Argentina [14, 41, 88-90], 4 from Puerto Rico [91-94], and 1 from Colombia [95] and Chile [96]. Five studies correspond to SLE LUMINA (LUpus in MInorities: nature versus nurture) multiethnic cohort $[16-18,85,86]$. The LUMINA cohort is comprised of patients of Hispanic (from Texas and Puerto Rico), African-American and Caucasian background. Two studies correspond to GLADEL'S (Grupo Latino Americano De Estudio de Lupus) longitudinal inception cohort $[14,97]$. Thirty studies were cross-sectional, 15 were case-controls, 11 were cohort, 2 nested case-control and 2 were an inception cohort. The flowchart for systematic literature review and articles included in the analysis are shown in Figure 1.

3.5. Prevalence, Risk Factors, and Subphenotypes of CVD. Out of total of 60 articles that fulfilled eligibility criteria, 46 had interpretable data regarding CVD frequency, which corresponds to a prevalence range of $4 \%-79.5 \%$. Several classic $\mathrm{CV}$ risk factors such as metabolic syndrome (MetS), obesity, dyslipidemia, hypertension, T2DM, sedentary lifestyle, male gender, smoking, advanced age, hyperhomocysteinemia, renal impairment, family history of CVD, and menopausal status were described. Several studies reported nontraditional risk factors such as ancestry, certain single-nucleotide polymorphisms, SLE per se, polyautoimmunity, autoantibodies (i.e., antiphospholipid), markers of systemic inflammation 
TABLE 2: Cardiovascular disease characteristics of 310 patients with SLE.

\begin{tabular}{lc}
\hline & $\%(n / N)$ \\
\hline Clinical manifestation & \\
Cardiovascular disease & $36.5(113 / 310)$ \\
Hypertension & $25.2(78 / 310)$ \\
Stroke & $16.8(52 / 310)$ \\
Coronary disease & $2.6(8 / 310)$ \\
Thrombotic event & $1.6(5 / 310)$ \\
Carotid disease & $0.6(2 / 310)$ \\
\hline Risk factors & \\
Type 2 diabetes mellitus & $1.9(6 / 309)$ \\
Dyslipidemia & $18.1(56 / 309)$ \\
Ever smoking & $39.21(120 / 306)$ \\
1 to 6 packages/year & $4.2(13 / 306)$ \\
6 to 15 packages/year & $2.6(8 / 306)$ \\
$\quad$ More than 15 packages/year & $2.3(7 / 306)$ \\
Quitter & $30.1(92 / 306)$ \\
Coffee consumption & $61.5(187 / 304)$ \\
1 to 2 cups/day & $30.9(94 / 304)$ \\
2 to 4 cups/day & $22.7(69 / 304)$ \\
More than 4 cups/day & $7.9(24 / 304)$ \\
Never & $38.5(117 / 304)$ \\
\hline Laboratories findings & \\
Abnormal triglycerides & $34.3(12 / 35)$ \\
Abnormal total cholesterol & $44.4(16 / 22)$ \\
Abnormal high-density cholesterol & $58.8(20 / 34)$ \\
Abnormal low-density cholesterol & $33.3(8 / 24)$ \\
Abnormal glycemic & $25.7(9 / 35)$ \\
\hline
\end{tabular}

(i.e., CRP), SLE disease activity, SLE duration, organ damage, immune cells aberrations, medication (i.e., glucocorticoids), vasculopathy, lupus nephritis, endogenous dyslipidemia, bone mineral density, education level, and monthly income. A broad spectrum of CV subphenotypes including hypertension, IHD, CAD, ACS, MI, angina, CHF, stroke, thrombosis, peripheral arterial disease, subclinical atherosclerosis, and mortality due to CVD were described in LA individuals with SLE. For details, see Figure 2 and Supplementary Table S1.

\section{Discussion}

The analysis of Colombian patients with SLE discloses a high prevalence of CVD (36.5\%). In contrast, prospective North Americans cohort studies showed a prevalence and annual incidence of CVD between 6 and 10\%, and 1.5\%, respectively $[9,98,99]$. Meanwhile, a case control study on the British General Practice Research Database showed higher risk of CVD in patients with SLE than rheumatoid arthritis [100]. Furthermore, in Italian population, Doria et al. [101] demonstrated rates of $10-40 \%$ for subclinical atherosclerosis. This inconsistency may reflect methodological obstacles such as differences in the definition of CVD outcome. Since
CVD begins by endothelial dysfunction, hypertension was considered as the first subphenotype to be assessed.

4.1. Epidemiology of Atherosclerosis among Patients with SLE. Carotid plaque is prevalent in $21 \%$ of SLE patients under age of 35 and in up to $100 \%$ of those over age 65 [102]. The most striking example of raised risk of MI comes from the University of Pittsburgh SLE cohort, in which women with SLE aged 35-44 were $>50$ times more likely to experience MI than women without SLE from the Framingham Offspring study (RR 52.4; 95\% CI 21.6-98.5) [8, 98].

Independent predictive risk factors for CV events had been assessed in five large prospective cohorts of patients with SLE, including Baltimore $(1992, n=229)$ [103], Pittsburg $(1997, n=498)$ [98], LUMINA $(2004, n=546)$ [17], Toronto (2007, $n=561$ ) [104] and Systemic Lupus International Collaborating Clinics-Registry for Atherosclerosis (2010, $n=$ 637) [105]. These cohorts found association of diverse classic risk factors (i.e., older age at diagnosis, smoking, hypercholesterolemia, male gender, and hypertension), as well as novel risk factors (i.e., longer duration of SLE and glucocorticoid use, antiphospholipid antibodies, and neuropsychiatric lupus), with CVD in SLE patients $[105,106]$. In a recent metaanalysis, Schoenfeld et al. [8] showed that epidemiologic data strongly support that SLE patients are at elevated relative risk of CVD. The risks of $\mathrm{MI}, \mathrm{CHF}, \mathrm{CVA}$, and CVD mortality are all increased among SLE patients compared to general population risks. The variability regarding the relative importance of risk factors for CVD among SLE patients in past epidemiologic studies is likely due in part to different design methods and different patient and comparison groups.

4.2. CVD in Hispanics with SLE. CVD has been assessed in LUMINA multiethnic cohort and GLADEL's longitudinal inception cohort, which demonstrated differences in sociodemographic, clinical (i.e., subphenotypes), immunologic, and therapeutic characteristics, in SLE patients with CV events $[14-19,85,86,93]$. The present study adds further evidence about the high frequency of CVD in patients with SLE, their traditional risk factors (i.e., dyslipidemia, and smoking), and highlights coffee consumption as a factor for such a complication. Through the systematic review several factors and outcomes related to CVD were also identified (Table 6).

4.3. Cigarette Smoking and Coffee Consumption Independently Influence the Risk of Developing CVD. Several studies have assessed smoking as an independent risk factor for $\mathrm{CV}$ atherosclerotic disease [17, 107-111]. Gustafsson et al. [110] found that smoking may be the main traditional risk factor promoting increased CV risk in 208 SLE patients (RR 3.4, 95\% CI 1.3-9.2). Previously, the same group found that smoking was predictive of MI, stroke, peripheral vascular disease (PVD) or CV mortality among the same patient population [109]. Toloza et al. [17] prospectively followed SLE patients over a median follow-up of 73.8 months and compared those who had a CVD event to those who did not as part of the LUMINA study. Current cigarette use was significantly associated with a 3.7-times increased risk of 
TABLE 3: Characteristics associated with CVD in 310 patients with SLE.

\begin{tabular}{|c|c|c|c|c|}
\hline Characteristic & $\begin{array}{c}\text { Cardiovascular } \\
\text { disease } 113 / 310 \\
\%(n / N)\end{array}$ & $\begin{array}{c}\text { Noncardiovascular } \\
\text { disease } 197 / 310 \\
\%(n / N)\end{array}$ & OR (95\% CI) & $P$ \\
\hline \multicolumn{5}{|l|}{ Sociodemographic characteristic } \\
\hline Age (y) & Median (IQR): 40 (23) & Median (IQR): 36 (21) & & 0.059 \\
\hline Age at SLE onset (y) & Median (IQR): 30 (19) & Median (IQR): 26 (18) & & 0.175 \\
\hline Age of diagnosis (y) & Median (IQR): 34 (22) & Median (IQR): 28 (18) & & 0.041 \\
\hline Ever smoking & $50.9(57 / 112)$ & $37.1(73 / 194)$ & $1.75(1.09-2.61)$ & 0.019 \\
\hline Coffee & $70.5(79 / 112)$ & $55.2(108 / 192)$ & $1.94(1.19-3.18)$ & 0.009 \\
\hline Hair dye & $46(52 / 113)$ & $37.4(73 / 195)$ & $1.42(0.89-2.29)$ & 0.139 \\
\hline Pesticides & $3.5(4 / 113)$ & $1(2 / 197)$ & $3.56(0.64-19.75)$ & 0.122 \\
\hline \multicolumn{5}{|l|}{ Autoimmune disease(s) } \\
\hline MAS & $3.5(4 / 113)$ & $7.1(14 / 197)$ & $0.48(0.15-1.49)$ & 0.196 \\
\hline Familial autoimmunity in FDR & $19.5(22 / 113)$ & $25.4(50 / 197)$ & $0.71(0.40-1.25)$ & 0.235 \\
\hline RA & $0.9(1 / 113)$ & $5.6(11 / 197)$ & $0.15(0.01-1.19)$ & 0.062 \\
\hline APS & $16.8(19 / 113)$ & $4.1(8 / 197)$ & $4.77(2.01-11.31)$ & 0.0001 \\
\hline AITD & $4.4(5 / 113)$ & $9.1(16 / 197)$ & $0.52(0.18-1.47)$ & 0.213 \\
\hline \multicolumn{5}{|l|}{ Comorbidities } \\
\hline Type 2 diabetes mellitus & $3.5(4 / 113)$ & $1(2 / 197)$ & $3.56(0.64-19.75)$ & 0.196 \\
\hline Dyslipidemia & $28.3(32 / 113)$ & $12.2(24 / 197)$ & $2.83(1.56-5.11)$ & 0.0001 \\
\hline Fibromyalgia & $14.2(16 / 113)$ & $7.1(14 / 197)$ & $2.14(1.00-4.57)$ & 0.045 \\
\hline \multicolumn{5}{|l|}{ Treatment } \\
\hline Antimalarials & $77(87 / 113)$ & $82.7(163 / 197)$ & $0.69(0.39-1.23)$ & 0.217 \\
\hline Mycophenolate Mofetil & $19.5(22 / 113)$ & $13.7(27 / 197)$ & $1.52(0.82-2.82)$ & 0.181 \\
\hline Cytotoxics agents & $17.7(20 / 113)$ & $9.1(16 / 197)$ & $2.13(1.07-4.23)$ & 0.027 \\
\hline \multicolumn{5}{|l|}{ Clinical variable } \\
\hline Discoid lupus & $5.3(6 / 113)$ & $9.1(16 / 197)$ & $0.55(0.21-1.44)$ & 0.225 \\
\hline Alopecia & $41.5(47 / 113)$ & $51.3(101 / 197)$ & $0.67(0.42-1.08)$ & 0.101 \\
\hline Subacute & $6.2(7 / 113)$ & $3(6 / 197)$ & $2.10(0.68-6.41)$ & 0.239 \\
\hline Urticaria & $19.5(22)$ & $10.2(20 / 197)$ & $2.14(1.11-4.12)$ & 0.021 \\
\hline Vasculitis & $15(17 / 113)$ & $20.3(40 / 197)$ & $0.89(0.37-1.29)$ & 0.250 \\
\hline Neurological involvement & $13.3(15 / 113)$ & $8.1(16 / 197)$ & $1.73(0.82-3.65)$ & 0.146 \\
\hline Headache & $28.2(33 / 113)$ & $18.9(37 / 197)$ & $1.79(1.03-3.06)$ & 0.035 \\
\hline Psychosis & $7.1(8 / 113)$ & $3.8(7 / 197)$ & $2.08(0.72-5.86)$ & 0.164 \\
\hline Serositis & $37.2(42 / 113)$ & $23.9(47 / 197)$ & $1.88(1.14-3.12)$ & 0.013 \\
\hline Pleural effusion & $31.9(36 / 113)$ & $18.9(37 / 197)$ & $2.02(1.18-3.44)$ & 0.009 \\
\hline Hands edema & $32.7(37 / 113)$ & $15.9(33 / 197)$ & $2.41(1.40-4.16)$ & 0.0001 \\
\hline Renal involvement & $56.6(84 / 113)$ & $40.9(80 / 197)$ & $1.91(1.19-3.05)$ & 0.006 \\
\hline Nephrotic & $27.4(31 / 113)$ & $10.7(21 / 197)$ & $3.16(1.71-5.84)$ & 0.0001 \\
\hline Pulmonary haemorrhage & $3.5(4 / 113)$ & $0.5(1 / 197)$ & $7.19(0.79-65.16)$ & 0.061 \\
\hline \multicolumn{5}{|l|}{ Laboratory findings } \\
\hline Thrombocytopenia & $11.9(13 / 109)$ & $5.3(10 / 187)$ & $2.39(1.01-5.67)$ & 0.041 \\
\hline Leukopenia & $30.6(34 / 111)$ & $42.3(80 / 189)$ & $0.60(0.36-0.98)$ & 0.044 \\
\hline Lymphopenia & $71.6(78 / 109)$ & $78.7(148 / 188)$ & $0.68(0.39-1.17)$ & 0.163 \\
\hline Abnormal creatinine & $17(17 / 100)$ & $5.4(8 / 169)$ & $3.61(1.54-8.47)$ & 0.002 \\
\hline Abnormal creatinine clearance & $64.4(38 / 59)$ & $52.3(56 / 107)$ & $1.64(0.85-3.17)$ & 0.133 \\
\hline Proteinuria $(+)$ & $50(41 / 82)$ & $30(39 / 130)$ & $2.33(1.31-4.13)$ & 0.003 \\
\hline $\operatorname{aCLIgG}(+)$ & $40.7(35 / 88)$ & $29.7(44 / 149)$ & $1.62(0.93-2.82)$ & 0.087 \\
\hline Lupus anticoagulant $(+)$ & $58.5(24 / 41)$ & $45.9(29 / 61)$ & $1.66(0.74-3.70)$ & 0.211 \\
\hline
\end{tabular}

CVD: cardiovascular disease; SLE: systemic lupus erythematosus; OR: odds ratio; CI: confidence interval; IQR: interquartile range; SD: standard deviation; Y: years; MAS: multiple autoimmune syndrome; FDR: first-degree relatives; RA: rheumatoid arthritis; APS: antiphospholipid syndrome; AITD: autoimmune thyroid disease; aCL: anticardiolipin antibodies. 
TABLE 4: Factors associated with CVD in patients with SLE* .

\begin{tabular}{lcccc}
\hline Characteristic & $\beta$ & AOR & $95 \%$ CI & P \\
\hline Dyslipidemia & 0.971 & 2.64 & $1.32-5.28$ & 0.005 \\
Pleural effusion & 0.751 & 2.12 & $1.17-3.84$ & 0.013 \\
Ever smoking & 0.602 & 1.83 & $1.07-3.10$ & 0.025 \\
Coffee consumption & 0.559 & 1.75 & $1.01-3.04$ & 0.043 \\
Renal involvement & 0.476 & 1.61 & $0.94-3.84$ & 0.081 \\
\hline
\end{tabular}

CVD: cardiovascular disease; SLE: systemic lupus erythematosus; $\beta$ : $\beta$ coefficient; AOR: adjusted odds ratio; $95 \%$ CI: $95 \%$ confidence interval.

${ }^{*}$ The model was adjusted by gender and duration of the disease.

TABLE 5: Factors associated with CVD in patients with SLE including interaction between smoking and coffee consumption* .

\begin{tabular}{lcccc}
\hline Characteristic & $\beta$ & AOR & $95 \%$ CI & $P$ \\
\hline APS & 1.55 & 4.71 & $1.81-12.2$ & 0.001 \\
Dyslipidemia & 1.07 & 2.92 & $1.54-5.55$ & 0.001 \\
Pleural effusion & 0.78 & 2.19 & $1.20-3.98$ & 0.011 \\
Smoking and coffee & 0.60 & 1.82 & $1.05-3.13$ & 0.03 \\
\hline
\end{tabular}

CVD: cardiovascular disease; SLE: systemic lupus erythematosus; $\beta$ : $\beta$ coefficient; AOR: adjusted odds ratio; CI: confidence interval; APS: antiphospholipid syndrome.

${ }^{*}$ Adjusted by gender and duration of the disease including interaction between smoking and coffee consumption. $P$-values persisted significant despite the evaluation of the four possible combinations (i.e., smoking, coffee, smoking and coffee, none) through the adjustment of the multivariate model.

having a CVD event. In the PROFILE population, another multicenter, multiethnic study population, Bertoli et al. [111] found that smoking acted as an independent risk factor associated with a 2 -fold decrease in time to a $\mathrm{CV}$ event among 1,333 SLE patients over a 6.4-year follow-up period.

Several studies have evaluated the association between coffee consumption and CVD in the general population with controversial results. Two Dutch studies [112, 113] found no association between coffee intake, high blood pressure, and CVD. Despite the classification of coffee consumption differed among studies, some results suggest that habitual coffee consumption is associated with increased risk of hypertension [114]. In the same way, Klag et al. [115] demonstrated over many years of followup that coffee drinking is associated with small increases in blood pressure but appears to play a small role in the development of hypertension. When they compared with nondrinkers at baseline, coffee drinkers had a greater incidence of hypertension during follow-up (18.8\% versus. $28.3 \% ; P=0.03$ ). Relative risk ( $95 \%$ confidence interval) of hypertension associated with drinking 5 or more cups a day was 1.35 (0.87-2.08) for baseline intake and 1.60 (1.062.40) for intake over followup. Other effects attributed to coffee drinking are the increase in systemic vascular resistance, increased serum cholesterol levels, arterial stiffness, plasma rennin activity, epinephrine and norepinephrine, driving an unfavorable effect on endothelial function in healthy population [116]. On the other hand an Australia study [117] detected a negative association between coffee, hypertension, and MetS. Likewise, an increase in flow-mediated dilation and a decrease in CRP levels related to coffee drinking have been observed regardless of CAD $[118,119]$.

In order to isolate the interaction of smoking and coffee consumption, two regression models were made in which both the independent effect of coffee and smoking consumption on CVD as well as their interaction remains significant, demonstrating synergism between them (i.e., multiplicative effect). Otherwise, coffee consumption has not been evaluated systematically in SLE patients with CVD. However, since there is not a universal accepted tool for assessing coffee consumption, a bias concerning this variable is not precluded. Furthermore, membership bias could also exist because coffee consumption in Colombia is a well-defined tradition.

4.4. Traditional Risk Factors for CVD in SLE. Diverse lupus cohorts had shown the influence of advanced age, dyslipidemia, obesity, hypertension, and hyperhomocysteinemia, as classical risk factors for CVD $[109,120,121]$. Younger patients with SLE have the greatest relative risk compared to their healthy counterparts, but the absolute risk of CVD among SLE patients increases with advancing age [8]. de Souza et al. [58] observed that young Brazilian patients with SLE presented higher prevalence of carotid plaque than controls.

López-Jaramillo et al. [122] showed that the concentration of proinflammatory cytokines is higher in the LA population than in developed countries, suggesting a higher susceptibility to develop systemic low-degree inflammation at a given level of abdominal obesity, which contributes to the burden of CVD in this population. The inflammatory milieu of SLE leads to deregulation of lipid metabolism pathways, which contribute to the increased risk of atherosclerotic disease among these patients $[123,124]$. Five large cohort studies have shown hypercholesterolemia as a risk factor for CVD in SLE patients [98, 103, 125-127]. Our results confirm the role of dyslipidemia as an independent risk factor for CVD in LA patients with SLE $[50,52,53,58,60,62-64,66,80,81,83,84$, 89]. For more details see Table 6.

4.5. Nontraditional Risk Factors for CVD in SLE. It is well known that while traditional CVD risk factors are undoubtedly important in increasing the CVD risk among SLE patients, these do not fully account for the elevated risk of CVD in this population [9]. Thereby, SLE-associated factors play an important role in the premature atherosclerosis process characteristic of these patients $[128,129]$. Evidence strongly suggests that atherosclerotic plaque is largely driven 


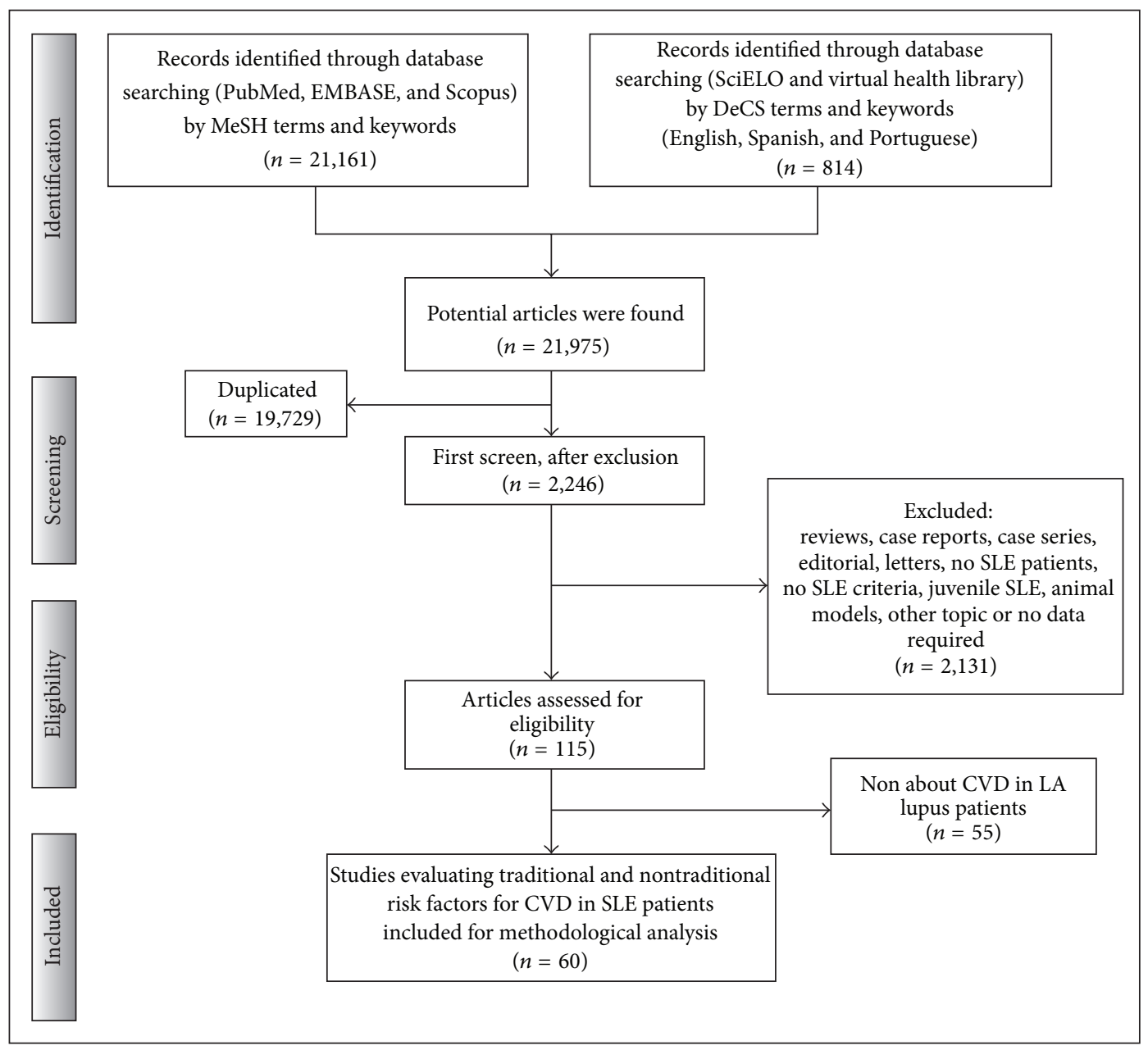

FIGURE 1: Flowchart of the systematic literature review. SLE: systemic lupus erythematosus, CVD: cardiovascular disease, LA: Latin America.

by inflammation and an active immunological response [130132] and points to SLE itself as an independent risk factor for premature CAD $[133,134]$. Nontraditional risk factors for CVD in ADs may be classified into genetics, AD-related, and miscellaneous $[135,136]$.

Family and twin studies have repeatedly supported a role for heredity in CAD, particularly in young individuals. Several genetic markers have been proposed as predisposing factors for CVD in SLE patients [87, 137, 138]. The SLEassociated risk factors represent a broad spectrum of conditions related to the autoimmune nature of the disease. All of these pathways may eventually converge into a shared proatherogenic phenotype [139]. Table 6 summarizes the state of the art of CVD risk factors in LA patients with SLE.

4.6. Assessment and Management of CV Risk in SLE Patients. Physicians often face the question of how to personalize treatment and prevention of $\mathrm{CV}$ events. Framingham risk score (FRS) is widely used to stratify asymptomatic patients into different $\mathrm{CV}$ risk categories in order to target the intensity of primary medical intervention. This score is strongly influenced by age and therefore has limited usefulness in young patients with SLE [140]. Therefore, evaluation of only traditional CAD risk factors in lupus patients may result in the underestimation of their future overall CAD risk. The contribution of inflammatory biomarkers should be also considered to gain a complete picture of the CAD risk in patients with underlying conditions that increase inflammation such as SLE [141]. The Reynolds Risk score incorporates CRP concentration in the risk model and reclassifies approximately $50 \%$ of women in the 10 -year FRS 5$20 \%$ risk category into different risk categories [142]. Another proposed approach corresponds to Systematic Coronary Risk Evaluation that is recommended by the EULAR experts and is widely used for CV assessment in patients with rheumatoid arthritis and other forms of inflammatory arthritis [143]. Neither of these charts includes the broad variety of risk factors that are disease-specific and could potentially explain the increased burden due to $\mathrm{CV}$ events. Therefore, $\mathrm{CV}$ risk in SLE patients is consistently underestimated with these scales.

Recently, Petri and Magder [144] proposed a data-driven risk equation of $\mathrm{CV}$ risk in SLE, based on data collected in a longitudinal cohort that can better estimate 10-year $\mathrm{CV}$ risk than the Framingham equation. In this model an integer score is given to each variable including age over 40, male gender, systolic blood pressure over 140, TC over 160, 


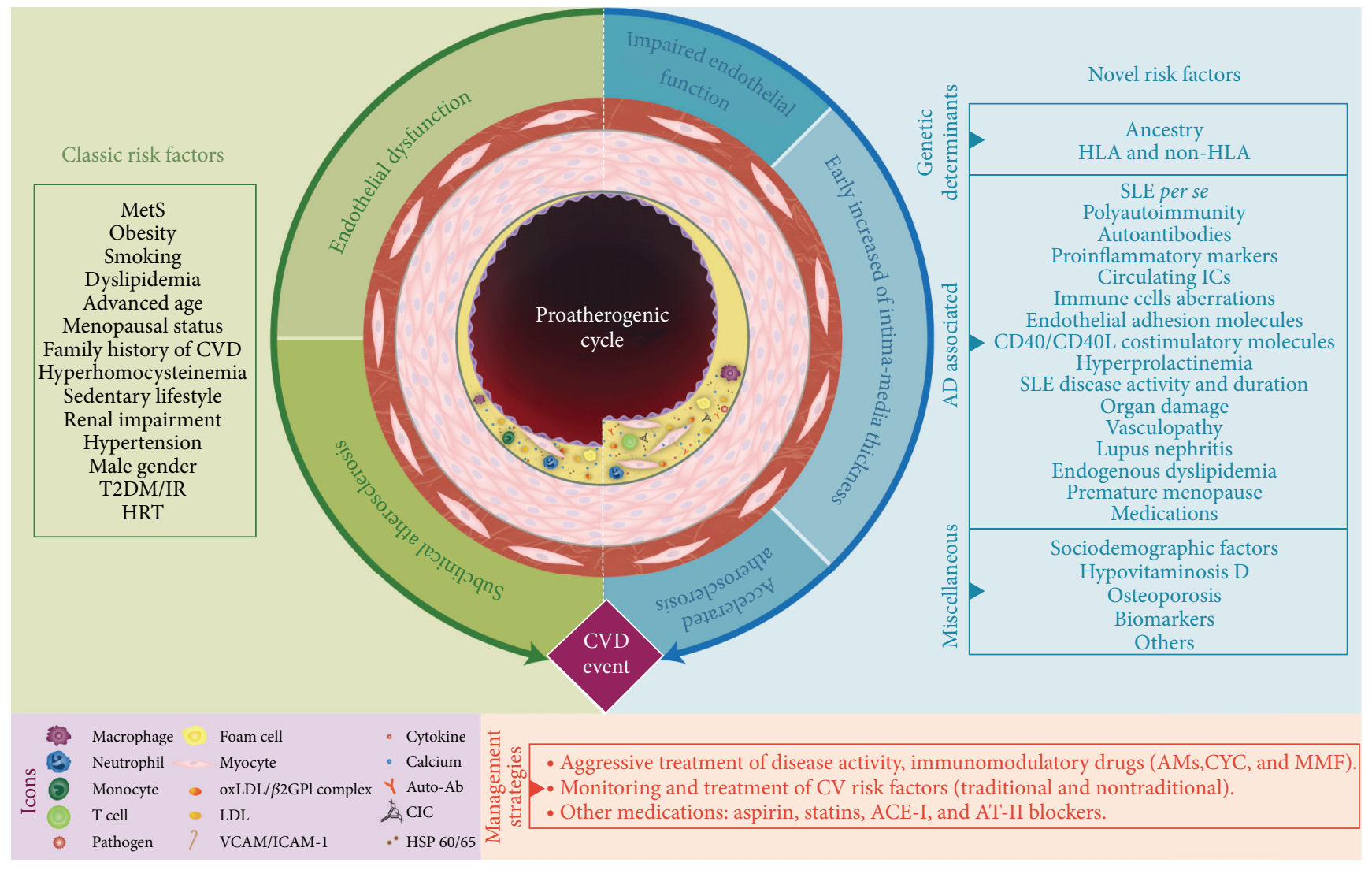

FIGURE 2: Traditional and autoimmune-related mechanisms of cardiovascular disease in systemic lupus erythematosus. A complex interaction between traditional and disease-specific traits leads to premature atherosclerotic process. Several risk factors (left) have been described since The Framingham Heart Study, known as classic risk factors, which over time conduce to endothelial dysfunction, subclinical atherosclerosis, and CV event manifest. In the autoimmune setting (right), a broad spectrum of novel risk factors contribute to development of premature vascular damage. This damage is represented by impaired endothelial function and early increased of Intima-Media Thickness which are surrogates of the accelerated atherosclerosis process, which is perpetuated by a chronic proinflammatory milieu. The cornerstone of management of CV risk include an aggressive treatment of disease activity, the continuous monitoring and treatment of modifiable CV risk factors, as well as the use of other medications in order to diminish de CV burden. CVD: cardiovascular disease, SLE: systemic lupus erythematosus, MetS: metabolic syndrome, T2DM: type 2 diabetes mellitus, IR: insulin resistance, HRT: hormone replacement therapy, CIC: Circulating Immune complex, oxLDL/B2GPI complex: oxidized-low density lipoprotein/ $\beta 2$ glycoprotein I, HDL: high density lipoprotein, Auto-Ab: auto-antibodies, AMs: antimalarials, CYC: cyclophosphamide, AZA: azathioprine, MMF: mycophenolate mofetil, ACEI: angiotensin-converting enzyme inhibitors, AT-II blockers: angiotensin II receptor blockers.

smoking, T2DM, mean SLE disease activity index (SLEDAI), history of lupus anticoagulant, and low mean C3. Using this model, together in the absence of SLE-specific risk factors, the estimated risk is higher than what would be projected based on the FRS. Nevertheless, this model is not exempt: limitations on, for example, HDL and LDL are not available at all routine visits. Further validation of this model is warranted.

SLE entails a CVD equivalent to T2DM; thus, lower lipid goals, aspirin use, and an aggressive monitoring are required $[145,146]$. Studies aimed to evaluate whether or not traditional treatment regimens prevent or slow atherosclerosis in SLE patients have been published [147]. The recent randomized controlled Lupus Atherosclerosis Prevention Study suggested that atorvastatin do not slow progression of subclinical atherosclerosis [148].

There are several new mechanisms of action described for antimalarials, many of them with beneficial effects in the management of CV risk in patients with SLE $[149,150]$.
There is evidence that antimalarials reduce serum cholesterol and LDL levels, elevate HDL cholesterol, and when taken concomitantly with steroids can reduce serum cholesterol [151]. Penn et al. [152] suggested that hydroxychloroquine use is associated with a lower fasting glucose and a decrease in the homeostasis model assessment-insulin resistance (HOMAIR) index. Rekedal et al. [153] showed that hydroxychloroquine initiation was associated with a significantly greater reduction in HbAlc as compared to methotrexate initiation among diabetic patients with rheumatic diseases. In addition, beneficial effects of hydroxycloroquine on thrombosis formation have also been described. Multiple retrospective cohort studies have shown a reduced incidence of thrombotic events and improved overall survival in patients with SLE treated with antimalarials [154-157].

The presence of low vitamin $\mathrm{D}$ levels has been associated with disrupting self-tolerance. Therefore, it is tempting to speculate that vitamin D might prove useful as a preventive 
TABLE 6: Traditional and nontraditional risk factors associated with cardiovascular disease and systemic lupus erythematosus in Latin America.

\begin{tabular}{|c|c|c|}
\hline $\begin{array}{l}\text { Risk factor associated } \\
\text { with CVD }\end{array}$ & Comments & Reference(s) \\
\hline \multirow{6}{*}{ Hypertension } & Traditional & \\
\hline & Hypertension influences the risk of death by CVD in SLE patients. & {$[64,89]$} \\
\hline & Hypertension acts as CVD subphenotype as well as a risk factor. & {$[45,49,71,88]$} \\
\hline & $\begin{array}{l}\text { Patients with SLE were at increased risk of thrombosis when it is associated with } \\
\text { hypertension. }\end{array}$ & {$[17,80,84]$} \\
\hline & $\begin{array}{l}\text { Compared with patients without atherosclerotic plaque, those with plaque had } \\
\text { higher prevalence of hypertension. }\end{array}$ & {$[54,63,66,73]$} \\
\hline & $\begin{array}{l}\text { Lupus patients with abnormal myocardial scintigraphic findings and hypertension, } \\
\text { as a risk factor for CAD, had a higher risk of abnormal findings on coronary } \\
\text { angiography. }\end{array}$ & {$[52,53]$} \\
\hline \multirow{5}{*}{ T2DM } & $\begin{array}{l}\text { Patients with lupus had higher hypertension prevalence than controls with } \\
\text { noninflammatory disorders. }\end{array}$ & {$[14,68,90]$} \\
\hline & $\begin{array}{l}\text { T2DM influence on abnormal myocardial perfusion in asymptomatic patients with } \\
\text { SLE. }\end{array}$ & {$[53]$} \\
\hline & $\begin{array}{l}\text { Alterations in glycemic profile were associated with traditional risk factors for CHD } \\
\text { and lupus characteristics, including CVD, damage index, and renal involvement. }\end{array}$ & {$[17,68,81]$} \\
\hline & $\begin{array}{l}\text { Patients with SLE and T2DM were at increased risk of thrombosis. This risk } \\
\text { remains elevated throughout the course of the disease. }\end{array}$ & {$[16,80]$} \\
\hline & T2DM is an independent risk factor for atherosclerotic plaque and CAC. & {$[63,71,84]$} \\
\hline \multirow{4}{*}{ Dyslipidemia } & $\begin{array}{l}\text { The main risk factor for death in SLE was heart involvement, which was influenced } \\
\text { by dyslipidemia. }\end{array}$ & {$[50,89]$} \\
\hline & $\begin{array}{l}\text { High levels of TGL were associated with myocardial perfusion abnormalities and } \\
\text { endothelial dysfunction }\end{array}$ & {$[52,53,83]$} \\
\hline & There was high prevalence of dyslipidemia as risk factor for thrombotic events. & {$[60,62,80]$} \\
\hline & $\begin{array}{l}\text { Alterations in lipid profile was a risk factor for premature CAC in young women } \\
\text { with SLE. }\end{array}$ & {$[66,84]$} \\
\hline \multirow{5}{*}{ Male gender } & CAD was more prevalent in dyslipidemic women with SLE than controls. & {$[64,81]$} \\
\hline & $\begin{array}{l}\text { Compared with patients without atherosclerotic plaque, those with plaque had high } \\
\text { level of TGL and LDL. }\end{array}$ & {$[58,63]$} \\
\hline & $\begin{array}{l}\text { Male gender was a risk factor for developing severe organ damage (CVD) and } \\
\text { mortality in SLE patients. }\end{array}$ & {$[16,17,53,60]$} \\
\hline & $\begin{array}{l}\text { Males with SLE were at increased risk of thrombosis and CAC. This risk remains } \\
\text { elevated throughout the course of the disease. }\end{array}$ & {$[80,84,85]$} \\
\hline & $\begin{array}{l}\text { Patients had more peripheral vascular and gonadal involvement compared with } \\
\text { published data from non-Hispanic SLE populations. }\end{array}$ & {$[76]$} \\
\hline \multirow{3}{*}{ MetS } & $\begin{array}{l}\text { SLE patients had a high prevalence of MetS that directly contributes to increasing } \\
\text { inflammatory status and oxidative stress. }\end{array}$ & {$[69]$} \\
\hline & $\begin{array}{l}\text { MetS was associated with traditional risk factors for } \mathrm{CHD} \text { and lupus characteristics, } \\
\text { including CVD, damage Index, and renal involvement. }\end{array}$ & {$[68,81]$} \\
\hline & Presence of MetS was related to CVD in SLE patients. & {$[90,94]$} \\
\hline \multirow{5}{*}{ Obesity } & $\begin{array}{l}\text { Patients with SLE who had excess weight present distinct clinical-laboratory } \\
\text { findings, sociodemographic characteristics, and treatment options when compared } \\
\text { to normal weight patients. }\end{array}$ & {$[17,71,81]$} \\
\hline & $\begin{array}{l}\text { Excess weight is associated with some traditional risk factors for CVD and SLE poor } \\
\text { prognosis. }\end{array}$ & {$[58,65,68]$} \\
\hline & $\begin{array}{l}\text { Increase weight influence on abnormal myocardial perfusion in asymptomatic } \\
\text { patients with SLE. }\end{array}$ & {$[53,64]$} \\
\hline & $\begin{array}{l}\text { SLE patients with high BMI have increased QT interval parameters when compared } \\
\text { to controls. This prolongation may lead to an increased CV risk. }\end{array}$ & [55] \\
\hline & Major values in BMI were related with the presence of CAD and carotid plaque. & {$[58,63,64]$} \\
\hline
\end{tabular}


TABLE 6: Continued.

\begin{tabular}{|c|c|c|}
\hline $\begin{array}{l}\text { Risk factor associated } \\
\text { with CVD }\end{array}$ & Comments & Reference(s) \\
\hline \multirow{5}{*}{ Smoking } & $\begin{array}{l}\text { Smoking is an important determinant in the occurrence of thrombotic (central } \\
\text { and/or peripheral, arterial and/or venous) events in SLE patients. }\end{array}$ & {$[18,69,81]$} \\
\hline & Smoking was an independent risk factor for atherosclerotic plaque and thrombosis. & {$[63,68,80]$} \\
\hline & $\begin{array}{l}\text { Smoking habit influence on abnormal myocardial perfusion in asymptomatic } \\
\text { patients with SLE. }\end{array}$ & {$[53]$} \\
\hline & Smoking was a risk factor for premature CAC in young women with SLE. & {$[66,84]$} \\
\hline & CAD was more prevalent in women with SLE. & {$[64,85,86]$} \\
\hline \multirow{4}{*}{ Advance age } & $\begin{array}{l}\text { Several traditional risk factors, including age, appear to be important contributors } \\
\text { to atherosclerotic } \mathrm{CV} \text { damage. }\end{array}$ & {$[16,71]$} \\
\hline & The presence of CVD has been associated with older age. & {$[16,59]$} \\
\hline & Age was directly related with atherosclerotic plaque formation. & {$[63]$} \\
\hline & $\begin{array}{l}\text { High percentage of SLE patients with abnormal angiographic findings was in } \\
\text { postmenopausal status. }\end{array}$ & {$[52]$} \\
\hline \multirow[t]{3}{*}{ Menopausal status } & There is high prevalence of premature menopausal status as a risk factor for CVD. & {$[60]$} \\
\hline & $\begin{array}{l}\text { Postmenopausal status was a risk factor for premature CAC in young women with } \\
\text { SLE. }\end{array}$ & {$[66,68,84]$} \\
\hline & $\begin{array}{l}\text { Postmenopausal women had a higher prevalence of subclinical AT and abnormal } \\
\text { myocardial perfusion in asymptomatic patients with SLE. }\end{array}$ & {$[53,63]$} \\
\hline \multirow{3}{*}{ Family history of CVD } & Familial history of CVD was an independent risk factor for atherosclerotic process. & {$[17,63,68]$} \\
\hline & $\begin{array}{l}\text { Family history of CVD was a risk factor for premature CAC in young women with } \\
\text { SLE. }\end{array}$ & {$[66,84]$} \\
\hline & $\begin{array}{l}\text { Family history of CVD influence on abnormal myocardial perfusion in } \\
\text { asymptomatic patients with SLE. }\end{array}$ & {$[53]$} \\
\hline HRT & $\begin{array}{l}\text { HRT use was not associated with the occurrence of vascular arterial events in the } \\
\text { LUMINA patients. HRT use in women with SLE should be individualized, but data } \\
\text { suggest its use may be safe if aPL antibodies are not present or vascular arterial } \\
\text { events have not previously occurred. }\end{array}$ & {$[17]$} \\
\hline \multirow{2}{*}{ Hyperhomocysteinemia } & Hyperhomocysteinemia was a risk factor for CAC in SLE patients. & {$[84]$} \\
\hline & $\begin{array}{l}\text { The presence of polyautoimmunity and hyperhomocysteinemia was risk factors for } \\
\text { thrombotic events. }\end{array}$ & {$[41]$} \\
\hline
\end{tabular}

Nontraditional

Genetic determinants

Ancestry

Non-HLA

SLE-associated

Poliautoimmunity
There are several differences regarding clinical (including CVD), prognostic, socioeconomic, educational, and access to medical care features in GLADEL cohort according to ancestry (White, Mestizo, and African-LA).

An SNP in FGG rs2066865 demonstrated association with arterial thrombosis risk in Hispanic Americans patients with SLE.

The CRP GT20 variant is more likely to occur in African-American and Hispanic SLE patients than in Caucasian ones, and SLE patients carrying the GT20 allele are more likely to develop vascular arterial events (LUMINA multiethnic cohort).

The presence of APS was the major independent contributor to the development of severe organ damage in Brazilian patients with SLE.

APS and its characteristic antibodies may contribute to the development of thrombotic events in Brazilian and Mexican lupus patients.

APS had high impact in CVD and survival in Brazilian lupus patients.

Polyautoimmunity (APS) may suggest concerted pathogenic actions with other autoantibodies in the development of thrombotic events in Mexican patients with SLE. 
TABle 6: Continued.

\begin{tabular}{|c|c|c|}
\hline $\begin{array}{l}\text { Risk factor associated } \\
\text { with CVD }\end{array}$ & Comments & Reference(s) \\
\hline \multirow[t]{2}{*}{ SLE per se } & $\begin{array}{l}\text { SLE diagnosis was significantly associated with carotid plaque formation and } \\
\text { development of CV event in Brazilian patients with SLE. }\end{array}$ & {$[58]$} \\
\hline & $\begin{array}{l}\text { High percentage of patients with abnormal angiographic findings had higher ACR } \\
\text { criteria number for SLE Brazilian patients with SLE. }\end{array}$ & {$[52]$} \\
\hline \multirow{8}{*}{ Autoantibodies } & $\begin{array}{l}\text { One of the independent predictors of vascular events in a multiethnic US cohort } \\
\text { (LUMINA) was the presence of any aPL antibody. }\end{array}$ & {$[17]$} \\
\hline & $\begin{array}{l}\text { anti- } \beta 2 \mathrm{GPI} \text { antibodies were strongly associated with thrombosis in patients with } \\
\text { Mexicans with SLE. The decrease of anti- } \beta 2 \text { GPI levels at the time of thrombosis } \\
\text { may indicate a pathogenic role. }\end{array}$ & [77] \\
\hline & $\begin{array}{l}\text { The higher frequency of aPT found in Mexican patients with SLE with thrombosis } \\
\text { may suggest concerted pathogenic actions with other autoantibodies in the } \\
\text { development of thrombotic events. }\end{array}$ & [78] \\
\hline & $\begin{array}{l}\text { Patients with aCL antibodies seem to be at an increased risk for arterial and venous } \\
\text { thrombotic events in Puerto Ricans and Chilean patients with SLE. }\end{array}$ & {$[92,96]$} \\
\hline & $\begin{array}{l}\text { There was correlation between lupus anticoagulant and thrombotic events in } \\
\text { Brazilian lupus patients. }\end{array}$ & {$[50]$} \\
\hline & $\begin{array}{l}\text { aCL antibodies were associated with thrombotic events, mainly in high titers in } \\
\text { Chilean SLE patients. }\end{array}$ & [96] \\
\hline & $\begin{array}{l}\text { aCL antibodies were significantly associated with CV events and showed an } \\
\text { association with echocardiographic abnormalities in Brazilian patients with SLE. }\end{array}$ & {$[51]$} \\
\hline & $\begin{array}{l}\text { Mexican patients had more peripheral vascular compared with published data from } \\
\text { non-Hispanic SLE populations. }\end{array}$ & {$[76]$} \\
\hline $\begin{array}{l}\text { Immune cells } \\
\text { aberrations }\end{array}$ & $\begin{array}{l}\text { Complement fixing activity of aCL antibodies seems to be relevant in thrombotic } \\
\text { venous events in Brazilian patients with SLE. }\end{array}$ & {$[57]$} \\
\hline \multirow[t]{2}{*}{ Inflammatory markers } & $\begin{array}{l}\text { Increased ESR was independently associated with MetS in Puerto Ricans lupic } \\
\text { patients. }\end{array}$ & {$[94]$} \\
\hline & $\begin{array}{l}\text { One of the independent predictors of vascular events in a multiethnic US cohort } \\
\text { (LUMINA) was elevated serum levels of CRP. }\end{array}$ & {$[16,17]$} \\
\hline \multirow{3}{*}{$\begin{array}{l}\text { Endogenous } \\
\text { dyslipidemia }\end{array}$} & $\begin{array}{l}\text { HDL distribution and composition ( }- \text { HDL } 2 b,+ \text { HDL3b, and }+ \text { HDL3c) were } \\
\text { abnormal in noncomplicated Mexican SLE patients. }\end{array}$ & [79] \\
\hline & $\begin{array}{l}\text { Low HDL levels and increased TGL levels were associated with atherosclerosis by } \\
\text { cIMT measurement in Colombian lupic patients. }\end{array}$ & {$[95]$} \\
\hline & $\begin{array}{l}\text { SLE patients have a lipid profile abnormality in Brazilian patients with SLE. This } \\
\text { pattern of dyslipoproteinemia may increase the risk of developing CAD. }\end{array}$ & {$[47]$} \\
\hline \multirow{8}{*}{ Disease activity } & $\begin{array}{l}\text { Disease activity (SLAM) is an important determinant in the occurrence of } \\
\text { thrombotic (central and/or peripheral, arterial, and/or venous) events in the } \\
\text { LUMINA cohort. }\end{array}$ & {$[18]$} \\
\hline & $\begin{array}{l}\text { SLEDAI scores were positively correlated with BMI and WC in Brazilian population } \\
\text { with SLE. }\end{array}$ & {$[69]$} \\
\hline & $\begin{array}{l}\text { Higher disease activity was independently associated with MetS and thrombosis in } \\
\text { Puerto Ricans and Mexican SLE patients. }\end{array}$ & {$[80,94]$} \\
\hline & $\begin{array}{l}\text { Higher score of SLICC was associated with atherosclerotic plaque in Brazilian SLE } \\
\text { patients. }\end{array}$ & {$[58]$} \\
\hline & $\begin{array}{l}\text { High scores in diseases activity index (SLEDAI and SLICC) were associated with } \\
\text { myocardial perfusion abnormalities in Brazilian SLE patients. }\end{array}$ & {$[52]$} \\
\hline & $\begin{array}{l}\text { Brazilian SLE patients have a lipid profile abnormality which is aggravated by } \\
\text { disease activity and may reside in a defect of VLDL metabolism. }\end{array}$ & {$[47]$} \\
\hline & Disease activity was predictor of CAC in Mexican SLE patients. & {$[84]$} \\
\hline & $\begin{array}{l}\text { Higher disease activity was independently associated with MetS in Puerto Ricans } \\
\text { patients with SLE. }\end{array}$ & {$[94]$} \\
\hline
\end{tabular}


TABLE 6: Continued.

\begin{tabular}{|c|c|c|}
\hline $\begin{array}{l}\text { Risk factor associated } \\
\text { with CVD }\end{array}$ & Comments & Reference(s) \\
\hline \multirow{4}{*}{ Organ damage } & $\begin{array}{l}\text { Baseline and accrued damage increase mortality risk (including due to CVD) in } \\
\text { Brazilian patients with SLE. }\end{array}$ & {$[61]$} \\
\hline & $\begin{array}{l}\text { Mexican patients had more peripheral vascular involvement (measured by SDI), } \\
\text { compared with published data from non-Hispanic SLE populations. }\end{array}$ & {$[76]$} \\
\hline & $\begin{array}{l}\text { In Brazilian SLE patients, MetS was associated with both traditional risk factors for } \\
\text { CHD and lupus characteristics including damage index. }\end{array}$ & {$[68]$} \\
\hline & $\begin{array}{l}\text { There was a correlation between IMT and revised damage index (SLICC) in } \\
\text { Brazilian SLE patients. }\end{array}$ & {$[58]$} \\
\hline \multirow{4}{*}{ Long duration } & $\begin{array}{l}\text { Atherosclerotic CV damage in SLE is multifactorial, and disease-related factors } \\
\text { (including CRP levels and SDI at baseline) appear to be important contributors to } \\
\text { such an occurrence (LUMINA multiethnic cohort). }\end{array}$ & {$[16]$} \\
\hline & $\begin{array}{l}\text { Longer duration of SLE was associated with atherosclerotic plaque and CV events in } \\
\text { Brazilian population. }\end{array}$ & {$[58,59]$} \\
\hline & $\begin{array}{l}\text { A correlation between IMT and duration of the disease was found in Brazilian } \\
\text { patients with SLE. }\end{array}$ & {$[63]$} \\
\hline & $\begin{array}{l}\text { Disease duration was independent predictor for premature CAC in young Brazilian } \\
\text { women with SLE. }\end{array}$ & {$[66]$} \\
\hline \multirow{2}{*}{ Medications } & $\begin{array}{l}\text { PDN }>10 \mathrm{mg} / \text { day was independently associated with MetS in Puerto Ricans SLE } \\
\text { patients. }\end{array}$ & {$[94]$} \\
\hline & $\begin{array}{l}\text { In Brazilian SLE patients, there was a correlation between IMT and the duration of } \\
\text { PDN use. }\end{array}$ & {$[63]$} \\
\hline \multirow{4}{*}{ Vasculopathy } & $\begin{array}{l}\text { IHD was observed in two types of Mexican SLE patients: those with long-term } \\
\text { steroid therapy and those with frank episodes of vasculitis. }\end{array}$ & {$[73]$} \\
\hline & $\begin{array}{l}\text { Current vasculitis was associated with abnormal myocardial scintigraphy in } \\
\text { Brazilian patients with SLE. }\end{array}$ & {$[53]$} \\
\hline & $\begin{array}{l}\text { Puerto Ricans patients with SLE and RP seem to be at increased risk for arterial and } \\
\text { venous thrombotic events. }\end{array}$ & {$[92]$} \\
\hline & $\begin{array}{l}\text { IHD was observed in two types of Mexican SLE patients: those with long-term } \\
\text { steroid therapy and those with frank episodes of vasculitis. }\end{array}$ & {$[73]$} \\
\hline Renal involvement & $\begin{array}{l}\text { In Brazilian SLE patients, MetS was associated with traditional risk factors for CHD } \\
\text { and lupus characteristics, including damage index and renal involvement (nephritic } \\
\text { syndrome). }\end{array}$ & {$[68]$} \\
\hline \multicolumn{3}{|l|}{ Miscellaneous } \\
\hline $\mathrm{BMD}$ & $\begin{array}{l}\text { Decreased BMD was an independent predictor for premature CAC in Brazilian } \\
\text { young women with SLE. }\end{array}$ & {$[66]$} \\
\hline $\begin{array}{l}\text { Sociodemographic } \\
\text { factors }\end{array}$ & $\begin{array}{l}\text { A low education and monthly income were associated with MetS in Mexican } \\
\text { patients with SLE and RA. }\end{array}$ & {$[81]$} \\
\hline
\end{tabular}

aCL: anticardiolipins antibodies; ACR: American College of Rheumatology; anti- $\beta 2$ GPI: anti-beta2 glycoprotein 1 antibodies; aPT: antiprothrombin antibodies; aPL: antiphospholipid antibodies; APS: antiphospholipid syndrome; AT: atherosclerosis; BMD: bone mineral density; BMI: body mass index; CAC: coronary artery calcification; CAD: coronary artery disease; cIMT: carotid Intimal Medial Thickness; CHD: coronary heart disease; CRP: C-reactive protein; CV: cardiovascular; CVD: cardiovascular disease; ESR: erythrocyte sedimentation rate; GLADEL: Grupo Latino Americano De Estudio de Lupus; HDL: highdensity lipoprotein cholesterol; HRT: hormone replacement therapy; IHD: ischemic heart disease; IMT: intimal media thickness; LA: Latin America; LDL: lowdensity lipoprotein cholesterol; LUMINA: LUpus in MInorities: NAture versus nurture cohort; MetS: metabolic syndrome; PDN: prednisolone; RP: Raynaud's phenomenon; T2DM: type 2 diabetes mellitus; TGL: triglycerides; SLAM: Systemic Lupus Activity Measure; SLE: systemic lupus erythematosus; SLEDAI: systemic lupus erythematosus disease activity index; SLICC: Systemic Lupus International Collaborating Clinics score; SDI: SLICC damage index; SNP: singlenucleotide polymorphism; VLDL: very low-density lipoprotein cholesterol; WC: waist circumference.

agent by reducing the risk of developing an autoimmune response [158]. In addition, vitamin $\mathrm{D}$ has been found to have antithrombotic properties improving the risk of CVD. Vitamin D deficiency has been linked to the development of atherosclerosis. As a corollary, the use of vitamin D may be useful to improve microvascular endothelial function [158].

\section{Limitations of the Study}

As a cross-sectional study, it is placed at level 4 of evidence according to Oxford Evidence Based Medicine [40]. Although the study sample size is not negligible, it would have been more valuable to have had an appropirate followup to establish valid associations between CVD, novel risk factors, 
and SLE. This, in turn, could have improved both internal and external validities.

The diversity of parameters defining CVD in SLE precluded homogenization of analysis and assessment in the systematic review. Often, one or two CVD subphenotypes were assessed as primary outcomes but many did not consider general CVD compromise. Therefore, it was not possible to perform a meta-analysis and to establish true measures of association such as odds ratios. Finally, we acknowledge that publication bias may exist.

\section{Final Remarks and Conclusions}

CVD is a major cause of morbidity and mortality in SLE patients. SLE and CVD share common pathophysiology mechanisms (i.e., systemic and chronic inflammation) with secondary accelerated atherosclerosis. Since traditional risk factors do not completely explain the high rates of CVD in patients with SLE, novel risk factors related to autoimmunity are now recognized. In the current study classical risk factors such as dyslipidemia, coffee consumption, and smoking habit are highlighted, and SLE-related factors (i.e., SLEantiphospholipid syndrome polyautoimmunity, pleural effusion, and renal involvement) are confirmed. In addition, several factors associated with CVD in LA patients with SLE were reviewed. Altogether, our results should encourage preventive population strategies for CVD in patients with SLE $[106,159]$, aimed at facilitating the suppression of cigarette smoking and coffee consumption as well as to the tight control of dyslipidemia and other modifiable risk factors.

\section{Conflict of Interests}

The authors have indicated that they have no conflict of interests regarding the content of this paper.

\section{Author's Contribution}

Jenny Amaya-Amaya and Juan Camilo Sarmiento-Monroy contributed equally to this work.

\section{Acknowledgments}

The authors thank all patients for their participation in the study, José-Leonardo Pérez-Fernández, Ana Catalina Herrera Díaz, and colleagues at the Center for Autoimmune Diseases Research (CREA) for their fruitful discussions and contributions. This work was supported by the School of Medicine and Health Sciences, Universidad del Rosario, Bogotá, Colombia.

\section{References}

[1] Z. Liu and A. Davidson, "Taming lupus-a new understanding of pathogenesis is leading to clinical advances," Nature Medicine, vol. 18, pp. 871-882, 2012.

[2] G. C. Tsokos, "Mechanisms of disease: systemic lupus erythematosus," The New England Journal of Medicine, vol. 365, no. 22, pp. 2110-2121, 2011.
[3] S. G. Guerra, T. J. Vyse, and D. S. C. Graham, "The genetics of lupus: a functional perspective," Arthritis Research and Therapy, vol. 14, article 211, 2012.

[4] D. P. D'Cruz, M. A. Khamashta, and G. R. Hughes, "Systemic lupus erythematosus," The Lancet, vol. 369, no. 9561, pp. 587596, 2007.

[5] M. B. Urowitz, A. A. M. Bookman, B. E. Koehler, D. A. Gordon, H. A. Smythe, and M. A. Ogryzlo, "The bimodal mortality pattern of systemic lupus erythematosus," The American Journal of Medicine, vol. 60, no. 2, pp. 221-225, 1976.

[6] L. Björnådal, L. Yin, F. Granath, L. Klareskog, and A. Ekbom, "Cardiovascular disease a hazard despite improved prognosis in patients with systemic lupus erythematosus: results from a Swedish population based study 1964-95," Journal of Rheumatology, vol. 31, no. 4, pp. 713-719, 2004.

[7] A. Bitton and T. Gaziano, “The Framingham heart study's impact on global risk assessment," Progress in Cardiovascular Diseases, vol. 53, no. 1, pp. 68-78, 2010.

[8] S. R. Schoenfeld, S. Kasturi, and K. H. Costenbader, "The epidemiology of atherosclerotic cardiovascular disease among patients with SLE: a systematic review," Seminars in Arthritis and Rheumatism, vol. 43, no. 1, pp. 77-95, 2013.

[9] J. M. Esdaile, M. Abrahamowicz, T. Grodzicky et al., "Traditional Framingham risk factors fail to fully account for accelerated atherosclerosis in systemic lupus erythematosus," Arthritis and Rheumatism, vol. 44, no. 10, pp. 2331-2337, 2001.

[10] E. González Burchard, L. N. Borrell, S. Choudhry et al., "Latino populations: a unique opportunity for the study of race, genetics, and social environment in epidemiological research," The American Journal of Public Health, vol. 95, no. 12, pp. 21612168, 2005.

[11] A. L. Price, N. Patterson, F. Yu et al., "A genomewide admixture map for latino populations," The American Journal of Human Genetics, vol. 80, no. 6, pp. 1024-1036, 2007.

[12] E. Lora, "Health perceptions in Latin America," Health Policy and Planning, vol. 27, pp. 555-569, 2012.

[13] S. M. Barreto, J. J. Miranda, J. P. Figueroa et al., "Epidemiology in Latin America and the Caribbean: current situation and challenges," International Journal of Epidemiology, vol. 41, no. 2, pp. 557-571, 2012.

[14] B. A. Pons-Estel, L. J. Catoggio, M. H. Cardiel et al., "The GLADEL multinational Latin American prospective inception cohort of 1,214 patients with systemic lupus erythematosus: ethnic and disease heterogeneity among 'hispanics,' Medicine, vol. 83, no. 1, pp. 1-17, 2004.

[15] S. Chaiamnuay, A. M. Bertoli, M. Fernández et al., “The impact of increased body mass index on systemic lupus erythematosus: data from LUMINA, a multiethnic cohort (LUMINA XLVI) [corrected]," Journal of Clinical Rheumatology, vol. 13, no. 3, pp. 128-133, 2007.

[16] G. J. Pons-Estel, L. A. González, J. Zhang et al., "Predictors of cardiovascular damage in patients with systemic lupus erythematosus: data from LUMINA (LXVIII), a multiethnic US cohort," Rheumatology, vol. 48, no. 7, pp. 817-822, 2009.

[17] S. M. A. Toloza, A. G. Uribe, G. McGwin Jr. et al., "Systemic lupus erythematosus in a multiethnic US cohort (LUMINA): XXIII. Baseline predictors of vascular events," Arthritis and Rheumatism, vol. 50, no. 12, pp. 3947-3957, 2004.

[18] K. T. Ho, C. W. Ahn, G. S. Alarcón et al., "Systemic lupus erythematosus in a multiethnic cohort (LUMINA): XXVIII. Factors predictive of thrombotic events," Rheumatology, vol. 44, no. 10, pp. 1303-1307, 2005. 
[19] P. I. Burgos, G. McGwin Jr., J. D. Reveille, L. M. Vilá, and G. S. Alarcón, "Factors predictive of thrombotic events in LUMINA, a multi-ethnic cohort of SLE patients (LXXII)," Rheumatology, vol. 49, no. 9, Article ID keq140, pp. 1720-1725, 2010.

[20] E. L. Smith and R. H. Shmerling, "The American college of rheumatology criteria for the classification of systemic lupus erythematosus: strengths, weaknesses, and opportunities for improvement," Lupus, vol. 8, no. 8, pp. 586-595, 1999.

[21] M. C. Hochberg, "Updating the American college of rheumatology revised criteria for the classification of systemic lupus erythematosus," Arthritis and Rheumatism, vol. 40, no. 9, p. 1725, 1997.

[22] Colombia, Law no. 30, Public Service in Higher Education, 1992.

[23] Colombia, Law no. 115, General on education, 1994.

[24] C. Barragán-Martínez, C. A. Speck-Hernández, G. MontoyaOrtiz, R. D. Mantilla, J. M. Anaya, and A. Rojas-Villarraga, "Organic solvents as risk factor for autoimmune diseases: a systematic review and meta-analysis," PLoS ONE, vol. 7, no. 12, Article ID e51506, 2012.

[25] Y. Shoenfeld and R. Cervera, Diagnostic Criteria in Autoimmune Diseases, 2008.

[26] A. Rojas-Villarraga, J. Amaya-Amaya, A. Rodriguez-Rodriguez, R. D. Mantilla, and J. M. Anaya, "Introducing polyautoimmunity: secondary autoimmune diseases no longer exist," Autoimmune Diseases, vol. 2012, Article ID 254319, 9 pages, 2012.

[27] J. M. Anaya, R. Corena, J. Castiblanco, A. Rojas-Villarraga, and Y. Shoenfeld, "The kaleidoscope of autoimmunity: multiple autoimmune syndromes and familial autoimmunity," Expert Review of Clinical Immunology, vol. 3, no. 4, pp. 623-635, 2007.

[28] J. M. Anaya, “The autoimmune tautology," Arthritis Research and Therapy, vol. 12, no. 6, article 147, 2010.

[29] J. Cárdenas-Roldán, A. Rojas-Villarraga, and J. M. Anaya, "How do autoimmune diseases cluster in families? A systematic review and meta-analysis," BMC Medicine, vol. 11, article 73, 2013.

[30] D. W. Jones and J. E. Hall, "Seventh report of the joint national committee on prevention, detection, evaluation, and treatment of high blood pressure and evidence from new hypertension trials," Hypertension, vol. 43, no. 1, pp. 1-3, 2004.

[31] N. J. Stone, S. Bilek, and S. Rosenbaum, "Recent national cholesterol education program adult treatment panel III update: adjustments and options," The American Journal of Cardiology, vol. 96, no. 4, pp. 53E-59E, 2005.

[32] P. W. F. Wilson, R. B. D’Agostino, D. Levy, A. M. Belanger, H. Silbershatz, and W. B. Kannel, "Prediction of coronary heart disease using risk factor categories," Circulation, vol. 97, no. 18, pp. 1837-1847, 1998.

[33] S. M. Grundy, R. Pasternak, P. Greenland, S. Smith Jr., and V. Fuster, "Assessment of cardiovascular risk by use of multiplerisk-factor assessment equations: a statement for healthcare professionals from the American heart association and the American college of cardiology," Circulation, vol. 100, no. 13, pp. 1481-1492, 1999.

[34] Asia Pacific Cohort Studies Collaboration, "The impact of cardiovascular risk factors on the age-related excess risk of coronary heart disease," International Journal of Epidemiology, vol. 35, no. 4, pp. 1025-1033, 2006.

[35] American Diabetes Association, "Standards of medical care in diabetes-2012," Diabetes Care, vol. 35, supplement 1, pp. S11S63, 2012.
[36] Z. Reiner, A. L. Catapano, G. de Backer et al., "ESC/EAS Guidelines for the management of dyslipidaemias: the task force for the management of dyslipidaemias of the European society of cardiology (ESC) and the European atherosclerosis society (EAS)," European Heart Journal, vol. 32, no. 14, pp. 1769-1818, 2011.

[37] British Cardiac Society, British Hyperlipidaemia Association, British Hypertension Society, and British Diabetic Association, "Joint British recommendations on prevention of coronary heart disease in clinical practice: summary," The British Medical Journal, vol. 320, no. 7236, pp. 705-708, 2000.

[38] A. Liberati, D. G. Altman, J. Tetzlaff et al., "The PRISMA statement for reporting systematic reviews and meta-analyses of studies that evaluate health care interventions: explanation and elaboration," Journal of Clinical Epidemiology, vol. 62, pp. e1-34, 2009.

[39] F. J. Mateen, J. Oh, A. I. Tergas, N. H. Bhayani, and B. B. Kamdar, "Titles versus titles and abstracts for initial screening of articles for systematic reviews," Clinical Epidemiology, vol. 6, pp. 89-95, 2013.

[40] OCEBM Levels of Evidence Working Group, The Oxford 2011 Levels of Evidence, Oxford Centre for Evidence-Based Medicine, 2011.

[41] L. Onetti, S. Villafañe, E. Menso et al., "Hyperhomocystinemia as a thrombotic risk factor in patients suffering from systemic lupus erithematosus and antiphospholipid syndrome," Revista de la Facultad de Ciencias Médicas, vol. 62, no. 3, pp. 19-23, 2005.

[42] F. V. Signorelli, G. F. Salles, and J. A. Papi, "Antiphospholipid syndrome as predictor of mortality in Brazilian patients with systemic lupus erythematosus," Lupus, vol. 20, article 419, 2011.

[43] J. Cabiedes, A. R. Cabral, and D. Alarcon-Segovia, "Clinical manifestations of the antiphospholipid syndrome in patients with systemic lupus erythematosus associate move strongly with anti- $\beta 2$-glycoprotein-I than with antiphospholipid antibodies," Journal of Rheumatology, vol. 22, no. 10, pp. 1899-1906, 1995.

[44] C. J. Bastos, A. C. Queiroz, and R. Martinelli, "Cardiac involvement in systemic lupus erythematosus: anatomo-pathological study," Revista da Associação Médica Brasileira, vol. 39, no. 3, pp. 161-164, 1993.

[45] W. H. Chahade, E. I. Sato, J. E. Moura Jr., L. T. L. Costallat, and L. E. C. Andrade, "Occasional series: lupus around the world. Systemic lupus erythematosus in Sao Paulo, Brazil: a clinical and laboratory overview," Lupus, vol. 4, no. 2, pp. 100-103, 1995.

[46] L. J. Alves, L. Hydalgo, L. F. Rolim et al., "Clinical and laboratorial diagnosis of heart disease in systemic lupus erythematosus," Arquivos Brasileiros de Cardiologia, vol. 68, no. 2, pp. 79-83, 1997.

[47] E. F. Borba and E. Bonfá, "Dyslipoproteinemias in systemic lupus erythematosus: influence of disease, activity, and anticardiolipin antibodies," Lupus, vol. 6, no. 6, pp. 533-539, 1997.

[48] L. T. L. Costallat, C. P. L. C. Lia, N. L. Neto, R. M. Yamada, and A. M. Samara, "Causes of death in systemic lupus erythematosus," Revista Brasileira de Reumatologia, vol. 37, no. 4, pp. 205-209, 1997.

[49] M. C. B. T. Rocha, S. S. Teixeira, C. Bueno, M. B. G. Vendramini, R. P. Martinelli, and M. B. Santiago, "Demographic, clinical, and laboratory profile of 100 patients with systemic lupus erythematosus in the State of Bahia," Revista Brasileira de Reumatologia, vol. 40, no. 5, pp. 221-230, 2000.

[50] A. C. Travassos, M. C. Rocha, S. Souza, C. Brandao, J. F. Silva, and M. Santiago, "Freqtiencia dos anticorpos antifosfolfpides 
(aFL) em portadores de lupus eritematoso sistemico (LES) no Estado da Bahia," Revista Brasileira de Reumatologia, vol. 40, pp. 183-188, 2000.

[51] C. A. Falcão, I. C. Alves, W. H. Chahade, A. L. B. P. Duarte, and N. Lucena-Silva, "Echocardiographic abnormalities and antiphospholipid antibodies in patients with systemic lupus erythematosus," Arquivos Brasileiros de Cardiologia, vol. 79, no. 3, pp. 285-291, 2002.

[52] E. M. C. Sella, E. I. Sato, and A. Barbieri, "Coronary artery angiography in systemic lupus erythematosus patients with abnormal myocardial perfusion scintigraphy," Arthritis and Rheumatism, vol. 48, no. 11, pp. 3168-3175, 2003.

[53] E. M. C. Sella, E. I. Sato, W. A. Leite, J. A. O. Filho, and A. Barbieri, "Myocardial perfusion scintigraphy and coronary disease risk factors in systemic lupus erythematosus," Annals of the Rheumatic Diseases, vol. 62, no. 11, pp. 1066-1070, 2003.

[54] M. Soares, L. Reis, J. A. S. Papi, and C. R. L. Cardoso, "Rate, pattern and factors related to damage in Brazilian systemic lupus erythematosus patients," Lupus, vol. 12, no. 10, pp. 788794, 2003.

[55] C. R. L. Cardoso, M. A. O. Sales, J. A. S. Papi, and G. F. Salles, "QT-interval parameters are increased in systemic lupus erythematosus patients," Lupus, vol. 14, no. 10, pp. 846-852, 2005.

[56] M. C. B.T. da Rocha, M. J. P. Vilar, E. A. M. Freire, and M. B. Santiago, "Arterial occlusion in systemic lupus erythematosus: a good prognostic sign?" Clinical Rheumatology, vol. 24, no. 6 , pp. 602-605, 2005.

[57] M. M. Shinzato, C. Bueno, V. S. T. Viana, E. F. Borba, C. R. Gonçalves, and E. Bonfá, "Complement-fixing activity of anticardiolipin antibodies in patients with and without thrombosis," Lupus, vol. 14, no. 12, pp. 953-958, 2005.

[58] A. W. S. de Souza, F. S. Hatta, F. Miranda Jr., and E. I. Sato, "Atherosclerotic plaque in carotid arteries in systemic lupus erythematosus: frequency and associated risk factors," Sao Paulo Medical Journal, vol. 123, no. 3, pp. 137-142, 2005.

[59] B. F. A. Freire, R. C. da Silva, A. T. Fabro, and D. C. dos Santos, "Is systemic lupus erithematosus a new risk factor for atherosclerosis?" Arquivos brasileiros de cardiologia, vol. 87, no. 3, pp. 300-306, 2006.

[60] R. W. Telles, C. C. D. Lanna, G. A. Ferreira, M. A. P. de Carvalho, and A. Ribeiro, "Freqüência de doença cardiovascular aterosclerótica e de seus fatores de risco em pacientes com lúpus eritematoso sistêmico," Revista Brasileira de Reumatologia, vol. 47, pp. 165-173, 2007.

[61] C. R. L. Cardoso, F. V. Signorelli, J. A. S. Papi, and G. F. Salles, "Initial and accrued damage as predictors of mortality in Brazilian patients with systemic lupus erythematosus: a cohort study," Lupus, vol. 17, no. 11, pp. 1042-1048, 2008.

[62] C. R. L. Cardoso, F. V. Signorelli, J. A. Papi, and G. F. Salles, "Prevalence and factors associated with dyslipoproteinemias in Brazilian systemic lupus erythematosus patients," Rheumatology International, vol. 28, no. 4, pp. 323-327, 2008.

[63] R. W. Telles, C. C. D. Lanna, G. A. Ferreira, A. J. Souza, T. P. Navarro, and A. L. Ribeiro, "Carotid atherosclerotic alterations in systemic lupus erythematosus patients treated at a Brazilian university setting," Lupus, vol. 17, no. 2, pp. 105-113, 2008.

[64] R. A. M. Cadaval, J. E. Martinez, M. A. Mazzolin, R. G. T. Barros, and F. A. de Almeida, "Avaliação do risco coronariano em mulheres com lúpus eritematoso sistêmico," Revista Brasileira de Reumatologia, vol. 49, no. 6, 2009.

[65] F. D. M. M. dos Santos, M. C. Borges, M. I. T. D. Correia, R. W. Telles, and C. C. D. Lanna, "Assessment of nutritional status and physical activity in systemic lupus erythematosus patients," Revista Brasileira de Reumatologia, vol. 50, no. 6, pp. 631-645, 2010.

[66] G. G. Ribeiro, E. Bonfá, R. S. Neto et al., "Premature coronary artery calcification is associated with disease duration and bone mineral density in young female systemic lupus erythematosus patients," Lupus, vol. 19, no. 1, pp. 27-33, 2010.

[67] S. K. Shinjo, E. Bonfá, D. Wojdyla et al., "Antimalarial treatment may have a time-dependent effect on lupus survival: data from a multinational Latin American inception cohort," Arthritis and Rheumatism, vol. 62, no. 3, pp. 855-862, 2010.

[68] R. W. Telles, C. C. D. Lanna, G. A. Ferreira, and A. L. Ribeiro, "Metabolic syndrome in patients with systemic lupus erythematosus: association with traditional risk factors for coronary heart disease and lupus characteristics," Lupus, vol. 19, no. 7, pp. 803-809, 2010.

[69] M. A. B. Lozovoy, A. N. C. Simão, M. S. N. Hohmann et al., "Inflammatory biomarkers and oxidative stress measurements in patients with systemic lupus erythematosus with or without metabolic syndrome," Lupus, vol. 20, no. 13, pp. 1356-1364, 2011.

[70] D. C. C. Souza, A. H. Santo, and E. I. Sato, "Mortality profile related to systemic lupus erythematosus: a multiple cause-ofdeath analysis," Journal of Rheumatology, vol. 39, no. 3, pp. 496503, 2012.

[71] F. de Miranda Moura dos Santos, M. C. Borges, R. W. Telles, M. I. T. D. Correia, and C. C. D. Lanna, "Excess weight and associated risk factors in patients with systemic lupus erythematosus," Rheumatology International, vol. 33, pp. 681-688, 2013.

[72] J. Gobaira Maluf, A. Zghaib Abad, and P. A. R. López, “The heart in systemic lupus erythematosus. Study in 32 non-selected patients (author's transl)," Archivos del Instituto de Cardiologia de Mexico, vol. 52, no. 3, pp. 223-228, 1982.

[73] E. Badui, D. Garcia-Rubi, E. Robles et al., "Cardiovascular manifestations in systemic lupus erythematosus. Prospective study of 100 patients," Angiology, vol. 36, no. 7, pp. 431-441, 1985.

[74] G. J. Ruiz-Arguelles, A. Ruiz-Arguelles, D. Alarcon-Segovia et al., "Natural anticoagulants in systemic lupus erythematosus. Deficiency of protein S bound to C4bp associates with recent history of venous thromboses, antiphospholipid antibodies, and the antiphospholipid syndrome," Journal of Rheumatology, vol. 18, no. 4, pp. 552-558, 1991.

[75] M. Salazar-Paramo, I. G. de la Torre, M. J. Fritzler, S. Loyau, and E. Anglés-Cano, "Antibodies to fibrin-bound tissue-type plasminogen activator in systemic lupus erythematosus are associated with Raynaud's phenomenon and thrombosis," Lupus, vol. 5, no. 4, pp. 275-278, 1996.

[76] A. Zonana-Nacach, A. Camargo-Coronel, P. Yáñez et al., "Measurement of damage in 210 Mexican patients with systemic lupus erythematosus: relationship with disease duration," Lupus, vol. 7, no. 2, pp. 119-123, 1998.

[77] L. Gómez-Pacheco, A. R. Villa, C. Drenkard, J. Cabiedes, A. R. Cabral, and D. Alarcón-Segovia, "Serum anti- $\beta 2$-glycoproteinI and anticardiolipin antibodies during thrombosis in systemic lupus erythematosus patients," The American Journal of Medicine, vol. 106, no. 4, pp. 417-423, 1999.

[78] F. Salcido-Ochoa, J. Cabiedes, D. Alarcón-Segovia, and A. R. Cabral, "Antiprothrombin antibodies in patients with systemic lupus erythematosus or with primary antiphospholipid syndrome," Journal of Clinical Rheumatology, vol. 8, no. 5, pp. 251255, 2002. 
[79] J. G. Juárez-Rojas, A. X. Medina-Urrutia, R. Posadas-Sánchez et al., "High-density lipoproteins are abnormal in young women with uncomplicated systemic lupus erythematosus," Lupus, vol. 17, no. 11, pp. 981-987, 2008.

[80] J. Romero-Díaz, I. García-Sosa, and J. Sánchez-Guerrero, "Thrombosis in systemic lupus erythematosus and other autoimmune diseases of recent onset," Journal of Rheumatology, vol. 36, no. 1, pp. 68-75, 2009.

[81] A. Zonana-Nacach, E. Santana-Sahagún, F. J. Jiménez-Balderas, and A. Camargo-Coronel, "Prevalence and factors associated with metabolic syndrome in patients with rheumatoid arthritis and systemic lupus erythematosus," Journal of Clinical Rheumatology, vol. 14, no. 2, pp. 74-77, 2008.

[82] A. G. Uribe, J. Romero-Díaz, M. Apte et al., "Impact of immigration on the clinical expression of systemic lupus erythematosus: a comparative study of Hispanic patients residing in the USA and Mexico," Rheumatology, vol. 48, no. 11, pp. 1392-1397, 2009.

[83] E. Alexánderson, J. M. Ochoa, R. Calleja et al., "Endothelial dysfunction in systemic lupus erythematosus: evaluation with 13N-ammonia PET,' Journal of Nuclear Medicine, vol. 51, no. 12, pp. 1927-1931, 2010.

[84] J. Romero-Díaz, F. Vargas-Vóracková, E. Kimura-Hayama et al., "Systemic lupus erythematosus risk factors for coronary artery calcifications," Rheumatology, vol. 51, no. 1, pp. 110-119, 2012.

[85] S. M. A. Toloza, J. M. Roseman, G. S. Alarcón et al., "Systemic lupus erythematosus in a multiethnic US cohort (LUMINA): XXII. Predictors of time to the occurrence of initial damage," Arthritis and Rheumatism, vol. 50, no. 10, pp. 3177-3186, 2004.

[86] A. J. Szalai, G. S. Alarcón, J. Calvo-Alén et al., "Systemic lupus erythematosus in a multiethnic US cohort (LUMINA). XXX: association between C-reactive protein (CRP) gene polymorphisms and vascular events," Rheumatology, vol. 44, no. 7, pp. 864-868, 2005.

[87] R. Kaiser, Y. Li, M. Chang et al., "Genetic risk factors for thrombosis in systemic lupus erythematosus," Journal of Rheumatology, vol. 39, no. 8, pp. 1603-1610, 2012.

[88] S. Finkielman, N. M. Bleichmar, M. Norymberg, and A. Agrest, "Arterial hypertension in systemic lupus erythematosus," Medicina, vol. 29, no. 3, pp. 165-170, 1969.

[89] V. Bellomio, A. Spindler, E. Lucero et al., "Systemic lupus erythematosus: mortality and survival in Argentina. A multicenter study," Lupus, vol. 9, no. 5, pp. 377-381, 2000.

[90] A. Zonana-Nacach, E. Santana-Sahagún, F. J. Jiménez-Balderas et al., "Metabolic syndrome in Argentinean patients with systemic lupus erythematosus," Lupus, vol. 18, no. 11, pp. 1019-1025, 2009.

[91] L. M. Vilá, A. M. Mayor, A. H. Valentín, M. García-Soberal, and S. Vilá, "Clinical and immunological manifestations in 134 Puerto Rican patients with systemic lupus erythematosus," Lupus, vol. 8, no. 4, pp. 279-286, 1999.

[92] V. E. Rodriguez, E. N. Gonzalez-Pares, and C. Rivera, "Clinical manifestations and vascular events in patients with lupus erythematosus anticardiolipin antibodies and raynaud's phenomenon," Puerto Rico Health Sciences Journal, vol. 25, no. 4, pp. 307-313, 2006.

[93] M. Fernández, J. Calvo-Alén, A. M. Bertoli et al., "Systemic lupus erythematosus in a multiethnic US cohort (LUMINA L II): relationship between vascular events and the use of hormone replacement therapy in postmenopausal women," Journal of Clinical Rheumatology, vol. 13, no. 5, pp. 261-265, 2007.

[94] A. M. Negrón, M. J. Molina, A. M. Mayor, V. E. Rodríguez, and L. M. Vilá, "Factors associated with metabolic syndrome in patients with systemic lupus erythematosus from Puerto Rico," Lupus, vol. 17, no. 4, pp. 348-354, 2008.

[95] L. M. Yassin, J. Londoño, G. Montoya et al., "Atherosclerosis development in SLE patients is not determined by monocytes ability to bind/endocytose Ox-LDL," Autoimmunity, vol. 44, no. 3, pp. 201-210, 2011.

[96] P. Abumohor, C. Cerda, O. Neira et al., "Anticardiolipin antibodies in systemic lupus erythematosus: prevalence and clinical associations," Revista Medica de Chile, vol. 119, no. 5, pp. 517-523, 1991.

[97] D. Alarcón-Segovia, M. E. Alarcón-Riquelme, M. H. Cardiel et al., "Familial aggregation of systemic lupus erythematosus, rheumatoid arthritis, and other autoimmune diseases in 1,177 lupus patients from the GLADEL cohort," Arthritis and Rheumatism, vol. 52, no. 4, pp. 1138-1147, 2005.

[98] S. Manzi, E. N. Meilahn, J. E. Rairie et al., "Age-specific incidence rates of myocardial infarction and angina in women with systemic lupus erythematosus: comparison with the Framingham study," The American Journal of Epidemiology, vol. 145, no. 5, pp. 408-415, 1997.

[99] A. N. Kiani, L. Magder, and M. Petri, "Coronary calcium in systemic lupus erythematosus is associated with traditional cardiovascular risk factors, but not with disease activity," Journal of Rheumatology, vol. 35, no. 7, pp. 1300-1306, 2008.

[100] L. M. Fischer, R. G. Schlienger, C. Matter, H. Jick, and C. R. Meier, "Effect of rheumatoid arthritis or systemic lupus erythematosus on the risk of first-time acute myocardial infarction," The American Journal of Cardiology, vol. 93, no. 2, pp. 198-200, 2004.

[101] A. Doria, L. Iaccarino, A. Ghirardello et al., "Long-term prognosis and causes of death in systemic lupus erythematosus," The American Journal of Medicine, vol. 119, no. 8, pp. 700-706, 2006.

[102] T. Thompson, K. Sutton-Tyrrell, R. P. Wildman et al., "Progression of carotid intima-media thickness and plaque in women with systemic lupus erythematosus," Arthritis and Rheumatism, vol. 58, no. 3, pp. 835-842, 2008.

[103] M. Petri, S. Perez-Gutthann, D. Spence, and M. C. Hochberg, "Risk factors for coronary artery disease in patients with systemic lupus erythematosus," The American Journal of Medicine, vol. 93, no. 5, pp. 513-519, 1992.

[104] M. B. Urowitzx, D. Ibañez, and D. D. Gladman, "Atherosclerotic vascular events in a single large lupus cohort: prevalence and risk factors," Journal of Rheumatology, vol. 34, no. 1, pp. 70-75, 2007.

[105] M. B. Urowitz, D. Gladman, D. Ibañez et al., "Atherosclerotic vascular events in a multinational inception cohort of systemic lupus erythematosus," Arthritis Care and Research, vol. 62, no. 6, pp. 881-887, 2010.

[106] D. P. M. Symmons and S. E. Gabriel, "Epidemiology of CVD in rheumatic disease, with a focus on RA and SLE," Nature Reviews Rheumatology, vol. 7, no. 7, pp. 399-408, 2011.

[107] L. V. Scalzi, S. Bhatt, R. C. Gilkeson, and M. L. Shaffer, "The relationship between race, cigarette smoking and carotid intimal medial thickness in systemic lupus erythematosus," Lupus, vol. 18, no. 14, pp. 1289-1297, 2009.

[108] M. B. Urowitz, D. Gladman, D. Ibañez et al., "Clinical manifestations and coronary artery disease risk factors at diagnosis of systemic lupus erythematosus: data from an international inception cohort," Lupus, vol. 16, no. 9, pp. 731-735, 2007.

[109] J. Gustafsson, I. Gunnarsson, O. Börjesson et al., "Predictors of the first cardiovascular event in patients with systemic lupus 
erythematosus-a prospective cohort study," Arthritis Research and Therapy, vol. 11, no. 6, article R186, 2009.

[110] J. T. Gustafsson, J. F. Simard, I. Gunnarsson et al., "Risk factors for cardiovascular mortality in patients with systemic lupus erythematosus, a prospective cohort study," Arthritis Research and Therapy, vol. 14, article R46, 2012.

[111] A. M. Bertoli, L. M. Vilá, G. S. Alarcón et al., "Factors associated with arterial vascular events in PROFILE: a multiethnic lupus cohort," Lupus, vol. 18, no. 11, pp. 958-965, 2009.

[112] M. T. Driessen, L. L. J. Koppes, L. Veldhuis, D. Samoocha, and J. W. R. Twisk, "Coffee consumption is not related to the metabolic syndrome at the age of 36 years: the Amsterdam growth and health longitudinal study," European Journal of Clinical Nutrition, vol. 63, no. 4, pp. 536-542, 2009.

[113] C. S. P. M. Uiterwaal, W. M. M. Verschuren, H. B. Bueno-deMesquita et al., "Coffee intake and incidence of hypertension," The American Journal of Clinical Nutrition, vol. 85, no. 3, pp. 718-723, 2007.

[114] Z. Zhang, G. Hu, B. Caballero, L. Appel, and L. Chen, "Habitual coffee consumption and risk of hypertension: a systematic review and meta-analysis of prospective observational studies," The American Journal of Clinical Nutrition, vol. 93, no. 6, pp. 1212-1219, 2011.

[115] M. J. Klag, N. Y. Wang, L. A. Meoni et al., "Coffee intake and risk of hypertension: the Johns Hopkins precursors study," Archives of Internal Medicine, vol. 162, no. 6, pp. 657-662, 2002.

[116] A. Di Castelnuovo, R. Di Giuseppe, L. Iacoviello, and G. de Gaetano, "Consumption of cocoa, tea and coffee and risk of cardiovascular disease," European Journal of Internal Medicine, vol. 23, no. 1, pp. 15-25, 2012.

[117] S. H. Jee, J. He, P. K. Whelton, I. Suh, and M. J. Klag, “The effect of chronic coffee drinking on blood pressure: a meta-analysis of controlled clinical trials," Hypertension, vol. 33, no. 2, pp. 647652, 1999.

[118] M. Nardini, F. Natella, and C. Scaccini, "Role of dietary polyphenols in platelet aggregation. A review of the supplementation studies," Platelets, vol. 18, no. 3, pp. 224-243, 2007.

[119] M. Shechter, G. Shalmon, M. Scheinowitz et al., "Impact of acute caffeine ingestion on endothelial function in subjects with and without coronary artery disease," The American Journal of Cardiology, vol. 107, no. 9, pp. 1255-1261, 2011.

[120] E. Svenungsson, K. Jensen-Urstad, M. Heimbürger et al., "Risk factors for cardiovascular disease in systemic lupus erythematosus," Circulation, vol. 104, no. 16, pp. 1887-1893, 2001.

[121] M. J. Roman, J. E. Salmon, R. Sobel et al., "Prevalence and relation to risk factors of carotid atherosclerosis and left ventricular hypertrophy in systemic lupus erythematosus and antiphospholipid antibody syndrome," The American Journal of Cardiology, vol. 87, no. 5, pp. 663-666, 2001.

[122] P. López-Jaramillo, C. Velandia-Carrillo, J. Alvarez-Camacho, D. D. Cohen, T. Sánchez-Solano, and G. Castillo-López, "Inflammation and hypertension: are there regional differences?" International Journal of Hypertension, vol. 2013, Article ID 492094, 12 pages, 2013.

[123] M. McMahon, J. Grossman, B. Skaggs et al., "Dysfunctional proinflammatory high-density lipoproteins confer increased risk of atherosclerosis in women with systemic lupus erythematosus," Arthritis and Rheumatism, vol. 60, no. 8, pp. 2428-2437, 2009.

[124] M. McMahon, B. J. Skaggs, L. Sahakian et al., "High plasma leptin levels confer increased risk of atherosclerosis in women with systemic lupus erythematosus, and are associated with inflammatory oxidised lipids," Annals of the Rheumatic Diseases, vol. 70, no. 9, pp. 1619-1624, 2011.

[125] Z. Touma, D. D. Gladman, D. Ibañez, and M. B. Urowitz, "Ability of non-fasting and fasting triglycerides to predict coronary artery disease in lupus patients," Rheumatology, vol. 51, no. 3, Article ID ker339, pp. 528-534, 2012.

[126] J. Mikdashi, B. Handwerger, P. Langenberg, M. Miller, and S. Kittner, "Baseline disease activity, hyperlipidemia, and hypertension are predictive factors for ischemic stroke and stroke severity in systemic lupus erythematosus," Stroke, vol. 38, no. 2, pp. 281-285, 2007.

[127] M. Nikpour, M. B. Urowitz, D. Ibanez, P. J. Harvey, and D. D. Gladman, "Importance of cumulative exposure to elevated cholesterol and blood pressure in development of atherosclerotic coronary artery disease in systemic lupus erythematosus: a prospective proof-of-concept cohort study," Arthritis Research and Therapy, vol. 13, article R156, 2011.

[128] P. E. Westerweel, R. K. M. A. C. Luyten, H. A. Koomans, R. H. W. M. Derksen, and M. C. Verhaar, "Premature atherosclerotic cardiovascular disease in systemic lupus erythematosus," Arthritis and Rheumatism, vol. 56, no. 5, pp. 1384-1396, 2007.

[129] J. Frostegård, "Atherosclerosis in patients with autoimmune disorders," Arteriosclerosis, Thrombosis, and Vascular Biology, vol. 25, no. 9, pp. 1776-1785, 2005.

[130] E. Y. Rhew and R. Ramsey-Goldman, "Premature atherosclerotic disease in systemic lupus erythematosus-role of inflammatory mechanisms," Autoimmunity Reviews, vol. 5, no. 2, pp. 101-105, 2006.

[131] Y. Sherer and Y. Shoenfeld, "Mechanisms of disease: atherosclerosis in autoimmune diseases," Nature Clinical Practice Rheumatology, vol. 2, no. 2, pp. 99-106, 2006.

[132] M. McMahon, B. H. Hahn, and B. J. Skaggs, "Systemic lupus erythematosus and cardiovascular disease: prediction and potential for therapeutic intervention," Expert Review of Clinical Immunology, vol. 7, no. 2, pp. 227-241, 2011.

[133] M. Nikpour, M. B. Urowitz, and D. D. Gladman, "Premature atherosclerosis in systemic lupus erythematosus," Rheumatic Disease Clinics of North America, vol. 31, no. 2, pp. 329-354, 2005.

[134] L. E. Full, C. Ruisanchez, and C. Monaco, "The inextricable link between atherosclerosis and prototypical inflammatory diseases rheumatoid arthritis and systemic lupus erythematosus," Arthritis Research and Therapy, vol. 11, no. 2, article 217, 2009.

[135] J. C. Sarmiento-Monroy, J. Amaya-Amaya, J. S. EspinosaSerna, C. Herrera-Díaz, J. M. Anaya, and A. Rojas-Villarraga, "Cardiovascular disease in rheumatoid arthritis: a systematic literature review in latin america," Arthritis, vol. 2012, Article ID 371909, 17 pages, 2012.

[136] J. Amaya-Amaya, J. C. Sarmiento-Monroy, R. D. Mantilla, R. Pineda-Tamayo, A. Rojas-Villarraga, and J. M. Anaya, "Novel risk factors for cardiovascular disease in rheumatoid arthritis," Immunologic Research, vol. 56, no. 2-3, pp. 267-286, 2013.

[137] L. N. Troelsen, P. Garred, B. Christiansen, C. Torp-Pedersen, and S. Jacobsen, "Genetically determined serum levels of mannose-binding lectin correlate negatively with common carotid intima-media thickness in systemic lupus erythematosus," Journal of Rheumatology, vol. 37, no. 9, pp. 1815-1821, 2010.

[138] B. Marasini, M. Massarotti, M. de Monti, M. Erario, G. Ghilardi, and M. L. Biondi, "Genetic contribution to carotid vascular disease in patients with systemic lupus erythematosus," Journal of Clinical Immunology, vol. 28, no. 2, pp. 131-133, 2008. 
[139] J. M. Kahlenberg and M. J. Kaplan, "Mechanisms of premature atherosclerosis in rheumatoid arthritis and lupus," Annual Review of Medicine, vol. 64, pp. 249-263, 2013.

[140] V. K. Kawai, J. F. Solus, A. Oeser et al., "Novel cardiovascular risk prediction models in patients with systemic lupus erythematosus," Lupus, vol. 20, no. 14, pp. 1526-1534, 2011.

[141] P. W. F. Wilson, "Evidence of systemic inflammation and estimation of coronary artery disease risk: a population perspective," The American Journal of Medicine, vol. 121, no. 10, pp. S15-S20, 2008.

[142] P. M. Ridker, J. E. Buring, N. Rifai, and N. R. Cook, "Development and validation of improved algorithms for the assessment of global cardiovascular risk in women: the Reynolds risk score," The Journal of the American Medical Association, vol. 297, no. 6, pp. 611-619, 2007.

[143] M. J. L. Peters, D. P. M. Symmons, D. McCarey et al., "EULAR evidence-based recommendations for cardiovascular risk management in patients with rheumatoid arthritis and other forms of inflammatory arthritis," Annals of the Rheumatic Diseases, vol. 69, no. 2, pp. 325-331, 2010.

[144] M. Petri and L. Magder, "SLE cardiovascular risk equation," Lupus, vol. 22, no. 1, pp. 3-5, 2013.

[145] J. R. Elliott, S. Manzi, and D. Edmundowicz, "The role of preventive cardiology in systemic lupus erythematosus," Current Rheumatology Reports, vol. 9, no. 2, pp. 125-130, 2007.

[146] I. N. Bruce, "Cardiovascular disease in lupus patients: should all patients be treated with statins and aspirin?" Best Practice and Research: Clinical Rheumatology, vol. 19, no. 5, pp. 823-838, 2005.

[147] J. R. Elliott and S. Manzi, "Cardiovascular risk assessment and treatment in systemic lupus erythematosus," Best Practice and Research: Clinical Rheumatology, vol. 23, no. 4, pp. 481-494, 2009.

[148] M. A. Petri, A. N. Kiani, W. Post, L. Christopher-Stine, and L. S. Magder, "Lupus Atherosclerosis Prevention Study (LAPS)," Annals of the Rheumatic Diseases, vol. 70, no. 5, pp. 760-765, 2011.

[149] I. Ben-Zvi, S. Kivity, P. Langevitz, and Y. Shoenfeld, "Hydroxychloroquine: from malaria to autoimmunity," Clinical Reviews in Allergy and Immunology, vol. 42, no. 2, pp. 145-153, 2012.

[150] S. J. Katz and A. S. Russell, "Re-evaluation of antimalarials in treating rheumatic diseases: re-appreciation and insights into new mechanisms of action," Current Opinion in Rheumatology, vol. 23, no. 3, pp. 278-281, 2011.

[151] S. J. Morris, M. C. M. Wasko, J. L. Antohe et al., "Hydroxychloroquine use associated with improvement in lipid profiles in rheumatoid arthritis patients," Arthritis Care and Research, vol. 63, no. 4, pp. 530-534, 2011.

[152] S. K. Penn, A. H. Kao, L. L. Schott et al., "Hydroxychloroquine and glycemia in women with rheumatoid arthritis and systemic lupus erythematosus," Journal of Rheumatology, vol. 37, no. 6, pp. 1136-1142, 2010.

[153] L. R. Rekedal, E. Massarotti, R. Garg et al., "Changes in glycosylated hemoglobin after initiation of hydroxychloroquine or methotrexate treatment in diabetes patients with rheumatic diseases," Arthritis and Rheumatism, vol. 62, no. 12, pp. 35693573, 2010.

[154] R. Kaiser, C. M. Cleveland, and L. A. Criswell, "Risk and protective factors for thrombosis in systemic lupus erythematosus: results from a large, multi-ethnic cohort," Annals of the Rheumatic Diseases, vol. 68, no. 2, pp. 238-241, 2009.
[155] H. Jung, R. Bobba, J. Su et al., "The protective effect of antimalarial drugs on thrombovascular events in systemic lupus erythematosus," Arthritis and Rheumatism, vol. 62, no. 3, pp. 863-868, 2010.

[156] M. Petri, "Use of hydroxychloroquine to prevent thrombosis in systemic lupus erythematosus and in antiphospholipid antibody-positive patients," Current Rheumatology Reports, vol. 13, no. 1, pp. 77-80, 2011.

[157] G. S. Alarcón, G. McGwin, A. M. Bertoli et al., "Effect of hydroxychloroquine on the survival of patients with systemic lupus erythematosus: data from LUMINA, a multiethnic US cohort (LUMINA L)," Annals of the Rheumatic Diseases, vol. 66, no. 9, pp. 1168-1172, 2007.

[158] C. Perricone, N. Agmon-Levin, S. Colafrancesco, and Y. Shoenfeld, "Vitamins and systemic lupus erythematosus: to D or not to D," Expert Review of Clinical Immunology, vol. 9, no. 5, pp. 397-399, 2013.

[159] M. Mosca, C. Tani, M. Aringer et al., "European league against rheumatism recommendations for monitoring patients with systemic lupus erythematosus in clinical practice and in observational studies," Annals of the Rheumatic Diseases, vol. 69, no. 7, pp. 1269-1274, 2010. 


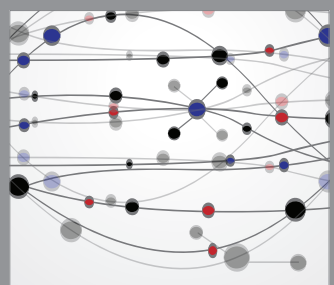

The Scientific World Journal
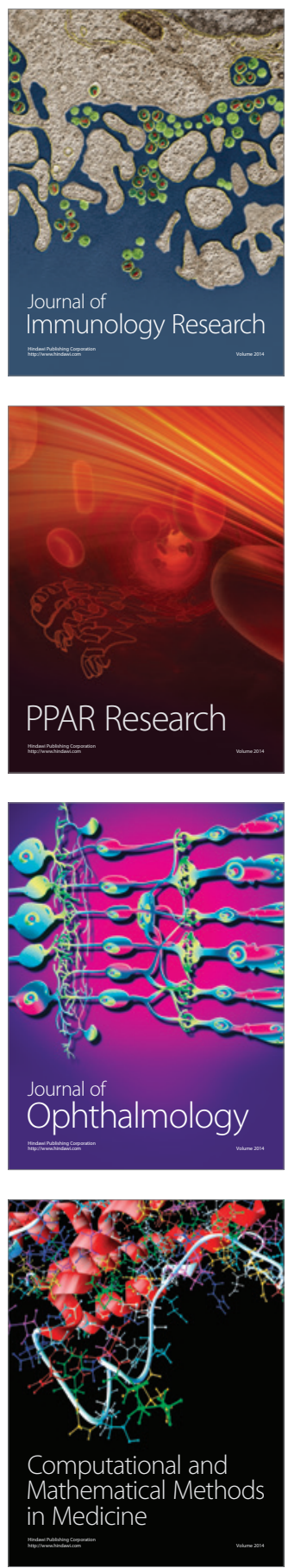

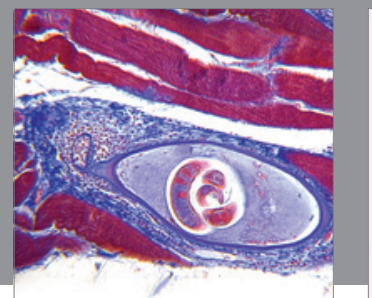

Gastroenterology

Research and Practice
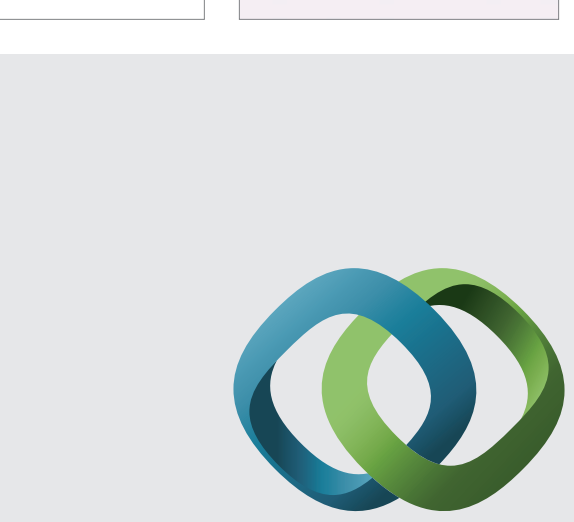

\section{Hindawi}

Submit your manuscripts at

http://www.hindawi.com
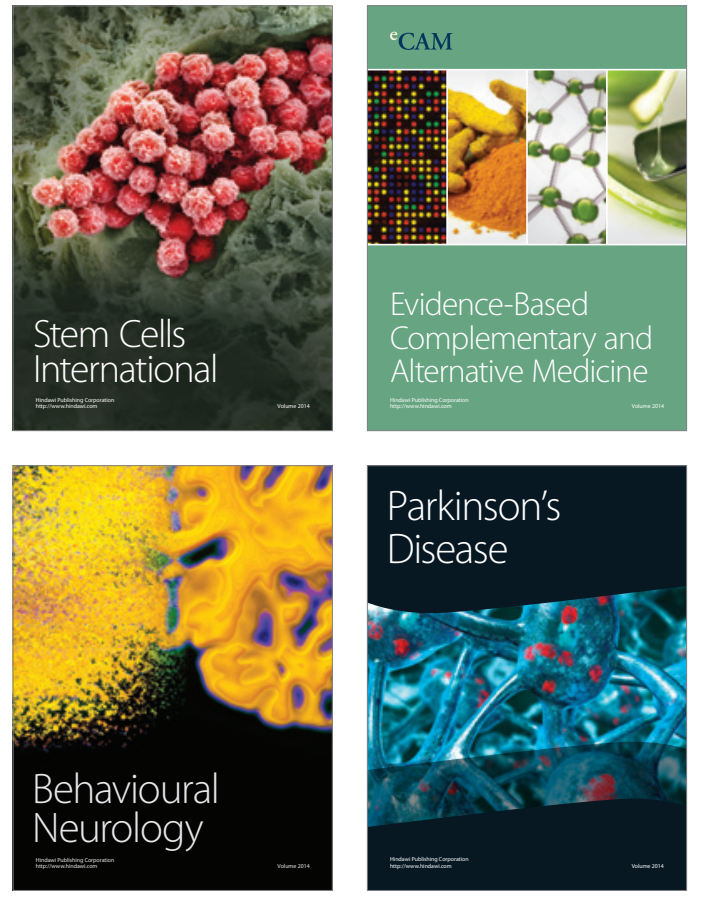
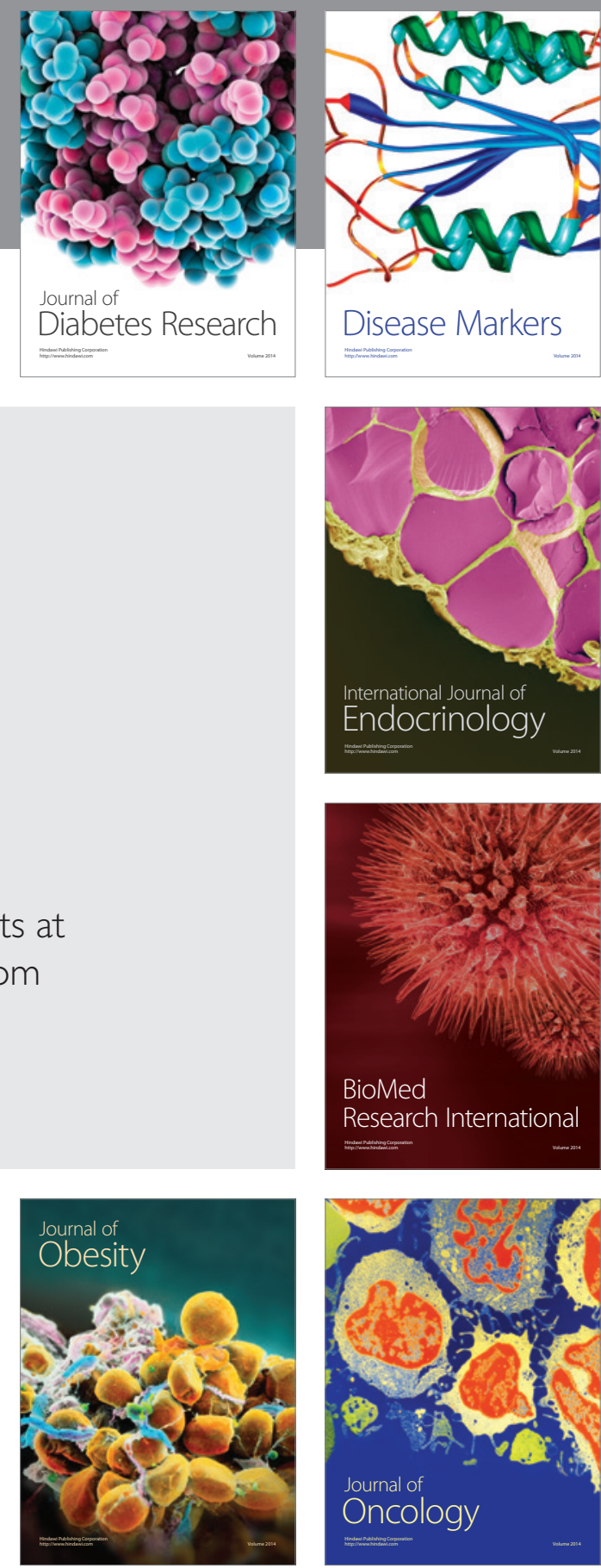

Disease Markers
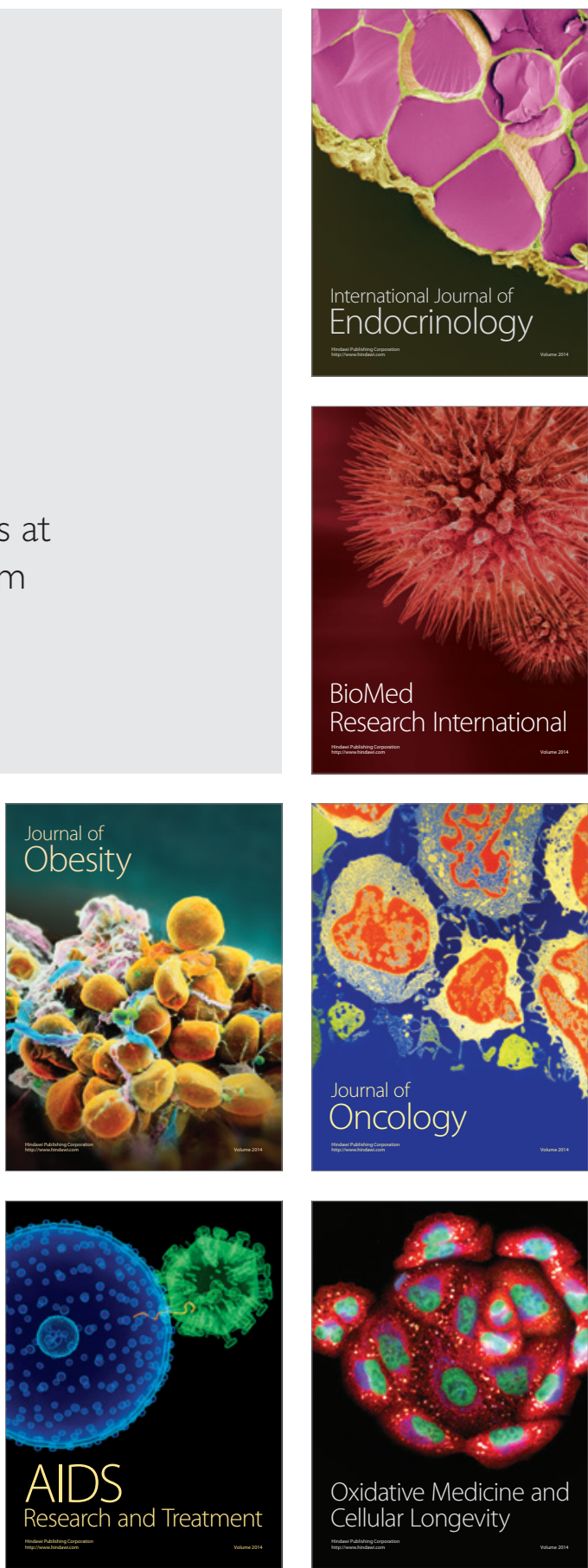